\title{
Dynamic Evaluation of Water Utilization Efficiency in Large Coal Mining Area Based on Life Cycle Sustainability Assessment Theory
}

\author{
Junyao Yang $\mathbb{D}$ and Liangliang Guo \\ College of Water Resources Science and Engineering, Taiyuan University of Technology, Taiyuan 030024, China \\ Correspondence should be addressed to Junyao Yang; yangjunyao@tyut.edu.cn and Liangliang Guo; guoliangliang@tyut.edu.cn
}

Received 23 June 2021; Revised 3 August 2021; Accepted 23 August 2021; Published 15 September 2021

Academic Editor: Zetian Zhang

Copyright (c) 2021 Junyao Yang and Liangliang Guo. This is an open access article distributed under the Creative Commons Attribution License, which permits unrestricted use, distribution, and reproduction in any medium, provided the original work is properly cited.

\begin{abstract}
Coal mining enterprises have a variety of water sources, complex drainage structures, long production chain, and many links, which lead to uncoordinated water utilization and low water efficiency. Taking a large coal mining area of China as an example, a dynamic model was established to evaluate the water utilization efficiency based on the Life Cycle Sustainability Assessment (LCSA) theory. In the model, the influence of five aspects (including resources, economy, technology, society, and environment) and 19 factors was considered. The game theory method was adopted to calculate the fusion weights of the 19 factors according to the analytic hierarchy process and CRITIC method. The CW-VIKOR method was used to explain the dynamic evaluation results of water efficiency in the coal mining area. The results show that the environmental impacts of the mining system mainly come from three aspects: regional drainage, domestic sludge landfill and disposal, and water system electricity consumption. Electricity consumption in water systems has the greatest environmental impact, accounting for about $73 \%$, regional drainage for about $26 \%$, and domestic sludge landfill and disposal for about $1 \%$.The CW-VIKOR approach can harmonize the interrelationships among resources, economy, technology, society, and environment. It is an effective method for LCSA of water resource in the coal mining area. The reliability of the evaluation results is high and close to the actual situation. The dynamic model established in this paper is also applicable to other coal mine areas, and only the factor weights need to be modified according to the specific characteristics of each coal mine. The model can provide guidance for optimal exploitation and allocation of coal mine water resources.
\end{abstract}

\section{Introduction}

China is both a major producer and consumer of coal. Coal is the main energy supply that underpins China's rapid economic growth. With the shortage of water resources and the increasing cost of water, as well as more and more stringent standards for wastewater discharge, it is imperative to improve the water recycling efficiency of coal enterprises. Coal enterprises have diversified water use sources, including surface water, groundwater, and reuse water. Meanwhile, its water use structure is complex, and different water use units have different requirements for water quality [1]. The reused water can only meet the low water quality requirements of coal mine production, coal preparation plant, and pit water sprinkling [2]. It results in a low reuse rate of reused water. In the mining activities of coal industry, water resources have the life cycle of water intake, water distribution, utilization, drainage, water treatment, and recycling/waste [3]. The multiple attributes of water resources determine that it has important influence on economy, environment, and energy in each stage of life cycle. It is of great practical significance for the rational development, optimal allocation, and sustainable utilization of coal mine water resources to carry out the comprehensive evaluation of the life cycle use and management of water resources in coal mine areas [4].

At present, the research on water resource sustainability mainly includes the research on the quantity and the quality of water resources $[5,6]$, water resource security $[7,8]$, water 
resource carrying capacity [9-11], water resource vulnerability $[12,13]$, and water resource utilization efficiency $[14,15]$.

The research on water resource utilization efficiency during coal mining can be summarized into two aspects. First, it focuses on the mine water quality treatment technology and the treatment rate improvement. For example, Zhou et al. [16] integrated two water treatment processes of pressurized air-water mutual flushing filter and aerated oxidation tank. They reused mine water in situ after using goaf to treat mine water, which achieved good results. Gu et al. [17] put forward the concept of channel-reservoir-use to protect and utilize the coal mine groundwater. Mao et al. [18] studied and applied zero discharge treatment technology according to the characteristics of mine water with high salinity in large coal bases in western China. He et al. [19] summarized the mature mode and new technology of mine water comprehensive utilization system. Second, some researchers studied the consumption and pollution of water resources in the process of coal mining. For example, Ding et al. [20] applied the whole life cycle theory to establish an evaluation model for the water footprint of energy production.

Lifecycle concept is a scientific approach to managing resource consumption and pollution. The nature life cycle of water resources refers to the whole life cycle of precipitation, runoff, confluence, and evaporation. Based on the natural and social attributes of water resources, Lundin et al. [21] divided the life cycle of water resources into four types: cycle, development, utilization, and recovery life cycle. Wang et al. [22] made a preliminary discussion on the theory of water resource life cycle from aspects of connotation, characteristics, flow of material quantity and value quantity of water resource life cycle, etc. Zhao et al. [23] analyzed the relationship between human system and water resource system in the life cycle of water resources utilization. They proposed the integrated management model of water resources life cycle based on the theory of harmonious between human and water. Based on the provincial energy input-output table in China, Zhang et al. [24] calculated the life-cycle water intake, water consumption, and wastewater discharge indexes of 8 types of energy varieties in China and calculated their environmental impacts using the Pfister method. Based on the life cycle assessment theory, Tong et al. [25] used the GaBi database to compare and quantify the impacts of industrial sewage reuse on the environment under different scenarios.

In terms of life cycle assessment research of the water supply system, Godskesen Berit [26] established the ASTA decision support system including environmental, economic, and social sustainability based on the ranking distribution weight and analytic hierarchy process of the multicriteria decision analysis method. The sustainability of water supply technology was evaluated by life cycle assessment, impact assessment of fresh water extraction, and multicriteria decision analysis. Studies have identified three phases that contribute significantly to the global environmental load: drainage, wastewater treatment, and construction of sewerage systems. Bhakar et al. [27] studied the potential environmental impacts of using groundwater as the source of irrigation and carried out a life cycle assess- ment of groundwater supply systems in severely arid areas of India to achieve sustainable groundwater management. The evaluation results show that the use of copper in the water supply system and the energy consumption during the mining process have a significant impact on the environment. Xue et al. [28] assessed the life-cycle environmental and economic impacts of urban water supply and wastewater systems in Greater Cincina. They illustrated the overall distribution of energy, resources, and costs in a typical urban centralized water supply system. Hadjikakou et al. [29] integrated multiregional input-output life cycle assessment, social impact analysis, and multiobjective decision analysis to establish a framework for sustainability assessment of water supply schemes. Garcia et al. [30] used the life cycle assessment method to assess the environmental and social impacts of Mexico's urban water supply system. They identified the stages and processes that have important impacts on the environment and society and analyze the significance of sustainable water supply system development.

Above all, there are still several aspects of water resource utilization in coal mine production that need further study: (1) lack of comprehensive evaluation model of water resource consumption for whole coal mining process; (2) lack of research on the comprehensive impact of water resource utilization in coal mine production on resources, economy, technology, society, and environment; and (3) lack of effective analysis methods of sensitive indexes affecting the water resource system for the whole coal mining process.

The establishment of the water resource life cycle evaluation system for the typical coal mining area and the identification of important indexes affecting the water circulation system of coal mines can provide scientific support for the improvement and optimization of the coal industry water use system [31, 32]. In this paper, taking a large coal mining area of China as an example, a dynamic model was established to evaluate the water utilization efficiency based on the Life Cycle Sustainability Assessment (LCSA) theory. In the model, the influence of five aspects (including resources, economy, technology, society, and environment) and 19 factors is considered. The game theory method was adopted to calculate the fusion weights of the 19 factors according to the analytic hierarchy process and CRITIC method. The CWVIKOR method was used to explain the dynamic evaluation results of water efficiency in the coal mining area.

\section{Overview of the Study Area}

China Coal Pingshuo Group Co., Ltd. is a super large coal production enterprise. Its reserves are 6.14 billion tons. In this paper, the research area is part of the Pingshuo coal mine. It mainly contains two surface mines (Antaibao and Anjialing) and two underground mines (Jinggong No.1 and Jinggong No.2) (Figure 1), with production capacity of 22 million t/a, 20 million t/a, 10 million t/a, and 10 million $\mathrm{t} / \mathrm{a}$, respectively. The four coal mine areas are selected as the research area to evaluate the sustainability of water resources during whole coal production process.

In the research area, the water sources for production and daily life include surface water, groundwater, reservoir 


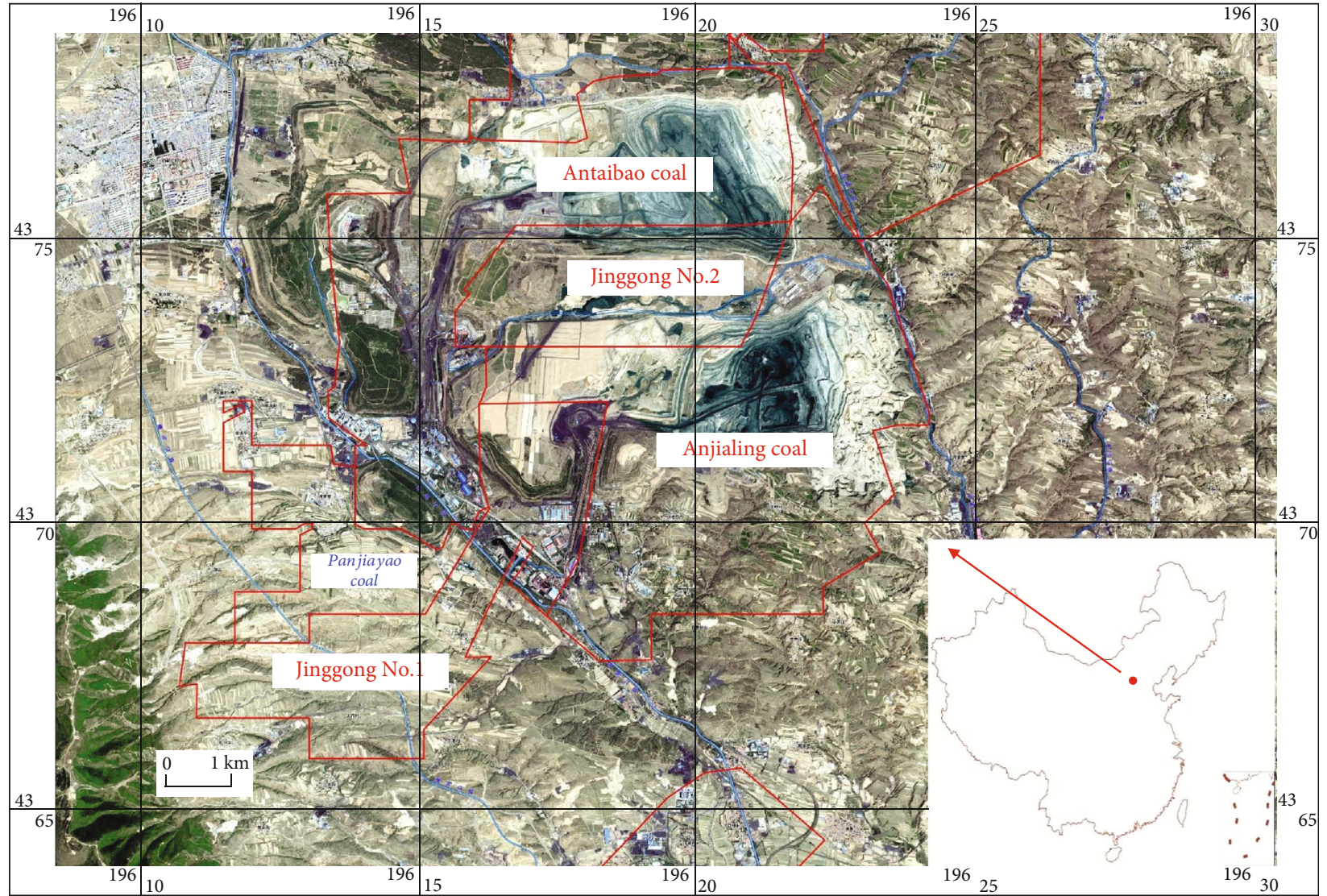

Figure 1: Location of the research area.

water, and reclaimed water. The surface water is supplied by the Yellow River with an annual water supply capacity of 5 million $\mathrm{m}^{3}$. The groundwater is from the Liujiakou water source region with an annual water supply capacity of 4.015 million $\mathrm{m}^{3}$. Regional sewage discharge points are scattered and cannot be collected in the form of gravity flow. The surface mines require large amount of water. Underground mining production needs less water, and the drainage points are more concentrated.

The research area has diversified water sources, complex drainage structure, long chain and many links, and complex changeable characterization indexes. Therefore, there exists water imbalance among different regions of the coal enterprise, which requires adjustment and optimization through scientific evaluation.

\section{Methodology}

Based on the LCSA theory, we established a life cycle evaluation model of coal mine water resources. The multiobjective decision analysis method was used to explain the evaluation results of the model. The sustainability of the life cycle of water resources in the mine area was analyzed. The methodology flow chart is shown in Figure 2.

3.1. Objectives and Scope. The research object of this paper mainly focuses on the whole circulation system of water resource life cycle in the research area. The data are obtained from 2015 to 2018.

In the sustainability assessment of the life cycle, the functional unit includes the annual operation status of water system from five dimensions, namely, resource consumption, economic benefit, technical performance, social impact, and environmental impact. The evaluation period of the functional unit is 1 year, and all inputs and outputs are based on this functional unit. System boundary includes physical boundary, geospatial boundary, and time series. The physical boundary is the six stages of water intake, water distribution, utilization, drainage, water treatment, and reuse/waste in the life cycle of water resources. The spatial boundary is the geographical boundary of the study area. The time boundary is from 2015 to 2018 .

\subsection{LCSA Lists}

\subsubsection{Environmental Impact List}

(1) Classification of Environmental Impact. The CML 2001 Mid-point Type Method, developed by the Centre for Environmental Sciences at Leiden University in the Netherlands [33], divides environmental impact types into three categories: (1) consumption of materials and energy, including abiotic and living resources; (2) environmental pollution, including acidification, eutrophication, ecological toxicity, human toxicity, and enhancement of greenhouse effect; 


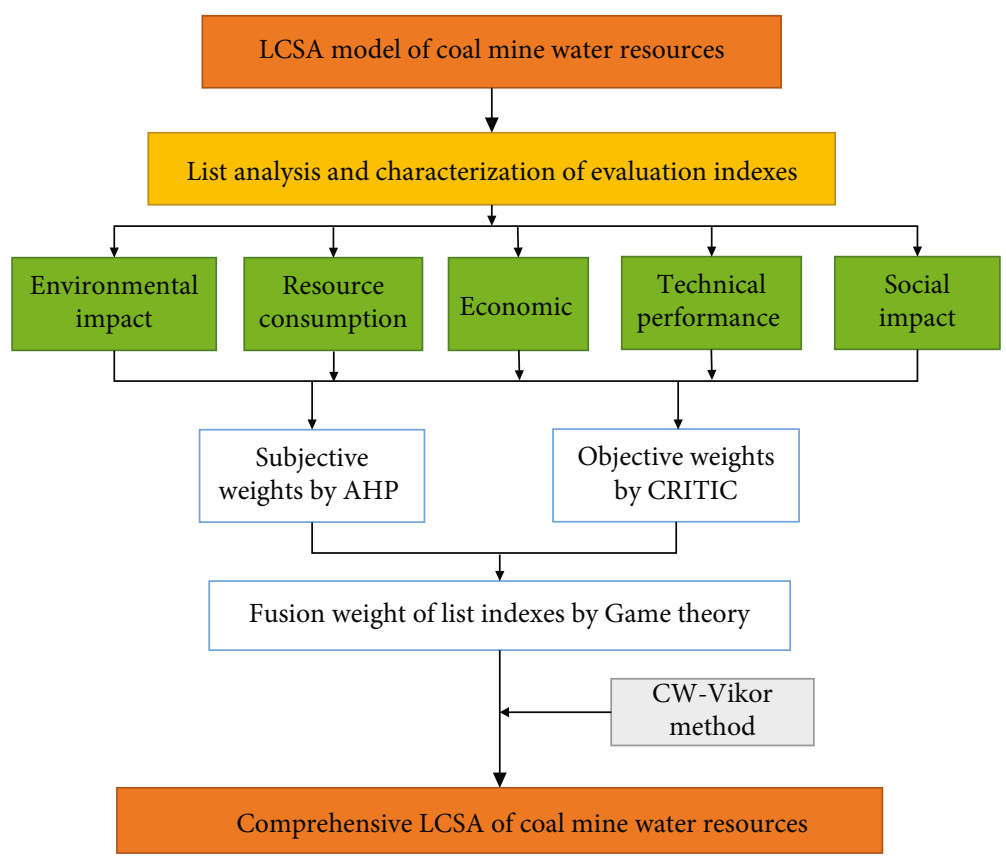

FIGURe 2: Methodology flow chart.

TABLE 1: Classification of environmental impacts and sources of pollutants.

\begin{tabular}{lcc}
\hline Classification & Associated pollutant & Source \\
\hline \multirow{4}{*}{ Global warming } & $\mathrm{CO}_{2}$ & Power supply, sludge disposal \\
& $\mathrm{CH}_{4}$ & Power supply, sludge disposal \\
& $\mathrm{NO}_{\mathrm{X}}$ & Sludge disposal \\
Sludge disposal \\
\hline Acidification & $\mathrm{N}_{2} \mathrm{O}$ & Power supply, sludge disposal \\
& $\mathrm{SO}_{2}$ & Sludge disposal \\
& $\mathrm{NO}_{\mathrm{X}}$ & Sludge disposal \\
Eutrophication & $\mathrm{NH}_{3}$ & Waste water discharge, sludge disposal \\
& $\mathrm{COD}_{3}$ & Waste water discharge, sludge disposal \\
& $\mathrm{NH}_{3}-\mathrm{N}$ & Waste water discharge \\
Human toxicity & $\mathrm{BOD}_{5}$ & Sludge disposal \\
& $\mathrm{TP}$ & Sludge disposal \\
\hline
\end{tabular}

and (3) environmental damage. The discharge of pollutants of coal mine water resources mainly includes power production, waste water discharge, and domestic sludge landfill disposal. In this paper, global warming potential, acidification potential, eutrophication potential, and human toxicity were selected and analyzed (Table 1).

(2) Characteristics of Environmental Impact and Index Standardization. Considering that pollutants include various phases, such as waste gas, waste water, and waste solids, the equivalent coefficient method is adopted for lifecycle assessment. The characterization and index standardization of each classification of environmental impacts are shown in Appendix A.

3.2.2. Resource Consumption List. Four indexes were selected to evaluate water resource utilization efficiency, including water resource utilization rate, fresh water supply ratio, industrial water reuse rate, and water consumption per ten thousand industrial added value.

Water resource utilization rate reflects the degree of water resources development and utilization. It is the percentage of the regional water utilization in the total available water resources. The amount of regional water utilization 
includes the consumption of Yellow River water, groundwater, and reclaimed water.

$$
U_{t i}=\frac{S_{u r}+G_{r d}+C_{y c}}{T_{o l}} \times 100 \%,
$$

where $U_{t i}$ denotes water resource utilization rate (\%), $S_{u r}$ denotes the consumption of Yellow River water $\left(\mathrm{m}^{3}\right), G_{r d}$ denotes the consumption of groundwater $\left(\mathrm{m}^{3}\right), C_{y c}$ denotes the consumption of reclaimed water $\left(\times 10^{4} \mathrm{~m}^{3}\right)$, and $T_{o l}$ denotes the amount of total available water resources in the research area $\left(\mathrm{m}^{3}\right)$.

Fresh water supply ratio refers to the proportion of the total fresh water consumption of each water use unit in the total water supply in the research area. It reflects the dependence degree of the research area on Yellow River water and groundwater.

3.2.3. Economic List. The economic list consists of three types: resource acquisition cost, operation cost, and economic benefit.

(1) Resource Acquisition Cost. Resource acquisition cost refers to the cost of water resources that need to be purchased during system operation.

(2) Operating Cost. Operation cost includes the sum of electricity, material, engineering cost, outsourced maintenance fee, safety fee, commuting fee, business contract fee, and labor fee paid during the operation of mine water system, domestic and industrial water system, underground water system, and reuse water system, etc.

(3) Economic Benefit. The economic benefit mainly includes the saved water resource purchasing fee through the reclaimed water reuse project and the saved environmental protection tax when the enterprise's wastewater is treated to meet the discharge standard.

$$
C_{3}=C_{\mathrm{re}}+C_{\mathrm{tax}}=P \times Q+\frac{\mathrm{eq}}{V_{p}} \times T,
$$

where $C_{3}$ denotes system economic benefit, $C_{\text {re }}$ denotes the saved water resource purchasing fee; $C_{\text {tax }}$ denotes the saved environmental protection tax, $P$ denotes the price of Yellow River water, $Q$ denotes reclaimed water reuse amount, eq denotes pollutant equivalent index, $V_{p}$ denotes discharge water quality, and $T$ denotes environmental protection tax.

The price of Yellow River water is $3.903 \mathrm{Yuan} / \mathrm{m}^{3}$. The pollutant equivalent index of $\mathrm{SS}, \mathrm{COD}, \mathrm{NH}_{3}-\mathrm{N}$, and $\mathrm{BOD}_{5}$ is $4 \mathrm{~kg}, 1 \mathrm{~kg}, 0.8 \mathrm{~kg}$ and $0.5 \mathrm{~kg}$, respectively. The environmental protection tax for each pollution equivalent of water pollutants is 2.1 Yuan.

3.2.4. Technical Performance List. The quantitative indexes of technical performance include average annual hydraulic load, suspended matter removal amount, COD removal amount, and $\mathrm{NH}_{3}-\mathrm{N}$ removal amount. The qualitative index is process stability. They were selected for quantitative measurement and objective description respectively.

Average annual hydraulic load refers to the percentage of the annual actual sewage treatment volume and the annual designed total sewage treatment volume. Process stability represents the adaptability of the water system to changes in water quantity and quality. It is quantified according to the scoring standard in Table 2.

3.2.5. Social Impact List. The contribution to labor positions during water resource system operation is used as the evaluation index of social impact. Meanwhile, perfection of the management system and conformation to environmental regulations are also taken as constraint indicators.

Contribution to labor positions refers to the number of labor posts during the operation of the clean water system, underground water treatment system, industrial and domestic sewage treatment system, and reuse water system. Perfection of the management system denotes whether the enterprise has a sound management organization and system of the water resource system. Conformation to environmental regulations refers to whether the production and operation of the water resource system conform to national and local environmental laws and regulation.

Perfection of the management system and conformation to environmental regulations are quantified using the scoring criteria in Table 3.

3.3. Comprehensive Evaluation of Water Resource Life Cycle Sustainability. A hierarchical model was established according to above evaluation indexes to conduct quantitative and qualitative evaluation. The evaluation steps included (1) classification according to evaluation index types (see Table 4). (2) Characterization: the evaluation indexes in each impact category are summarized. In order to eliminate the dimensionless inconsistency of variables, the range standardization method is used to process them and convert them into a unified computing unit. (3) Quantification: in this paper, the analytic hierarchy process (AHP) and CRITIC method are used to calculate the weight of each index of mining water resources. Then, the fusion weight is determined according to the game theory method. (4) Life cycle assessment: the CW-VIKOR method was used to evaluate the comprehensive utility value of the sustainability of regional water resources life cycle. The implementation process of steps (B.2)-(B.5) is shown in Appendix B.

\section{Results and Discussions}

\subsection{Water Resource Life Cycle List Analysis}

4.1.1. Environmental Impact List Analysis. The assessment of the environmental impact potential of water resources in the study area includes the following three aspects: (1) power is the main energy input. Actual power consumption data is obtained. (2) Sewage discharge: the average monitoring data of water quality of sewage treatment stations are adopted. (3) Sludge output: domestic sludge is transported to coal mine dumps for treatment. Only the environmental impact of safe 
TABLE 2: Scoring criteria.

\begin{tabular}{lccccc}
\hline Index & $10 \sim 8$ & $8 \sim 6$ & $6 \sim 4$ & $4 \sim 2$ & $2 \sim 0$ \\
\hline Process stability & Strong & Slightly strong & General & Weak & Weaker \\
\hline
\end{tabular}

TABLE 3: Scoring criteria.

\begin{tabular}{lccccc}
\hline Index & $10 \sim 8$ & $8 \sim 6$ & $6 \sim 4$ & & $4 \sim 2$ \\
\hline Perfection of the management system & Perfect & Good & General & Weak & Poor \\
Conformation to environmental regulations & Perfect & Good & General & Weak & Poor \\
\hline
\end{tabular}

TABLE 4: Evaluation system of water resource life cycle sustainability in research area.

\begin{tabular}{|c|c|c|c|c|}
\hline Target layer $(A)$ & Criteria Layer $(B)$ & Index layer $(C)$ & $\begin{array}{c}\text { Index } \\
\text { direction }\end{array}$ & $\begin{array}{c}\text { Index } \\
\text { properties }\end{array}$ \\
\hline \multirow{19}{*}{$\begin{array}{l}\text { Water life cycle } \\
\text { sustainability }(A)\end{array}$} & \multirow{4}{*}{$\begin{array}{c}\text { Resource } \\
\text { Consumption }\left(B_{1}\right)\end{array}$} & Water resource utilization rate $\left(C_{11}\right)$ & Negative & Quantitative \\
\hline & & Proportion of fresh water in water supply $\left(C_{12}\right)$ & Negative & Quantitative \\
\hline & & $\begin{array}{l}\text { Water consumption per ten thousand industrial value } \\
\qquad \text { added }\left(C_{13}\right)\end{array}$ & Negative & Quantitative \\
\hline & & Reuse rate of industrial water $\left(C_{14}\right)$ & Positive & Quantitative \\
\hline & \multirow{3}{*}{ Economy $\left(B_{2}\right)$} & Resource acquisition cost $\left(C_{21}\right)$ & Negative & Quantitative \\
\hline & & Operating cost $\left(C_{22}\right)$ & Negative & Quantitative \\
\hline & & Economic benefit $\left(C_{23}\right)$ & Positive & Quantitative \\
\hline & \multirow{5}{*}{$\begin{array}{l}\text { Technical Performance } \\
\qquad\left(B_{3}\right)\end{array}$} & Annual average hydraulic load $\left(C_{31}\right)$ & Negative & Quantitative \\
\hline & & Process stability $\left(C_{32}\right)$ & Positive & Qualitative \\
\hline & & Suspended solids removal amount $\left(C_{33}\right)$ & Positive & Quantitative \\
\hline & & COD removal amount $\left(C_{34}\right)$ & Positive & Quantitative \\
\hline & & Ammonia nitrogen removal capacity $\left(\mathrm{C}_{35}\right)$ & Positive & Quantitative \\
\hline & \multirow{3}{*}{ Social Impact $\left(B_{4}\right)$} & Contribution to labor positions $\left(C_{41}\right)$ & Positive & Quantitative \\
\hline & & Environmental laws and regulations $\left(C_{42}\right)$ & Positive & Qualitative \\
\hline & & Perfection of management system $\left(C_{43}\right)$ & Positive & Qualitative \\
\hline & \multirow{4}{*}{$\begin{array}{l}\text { Environmental Impact } \\
\qquad\left(B_{5}\right)\end{array}$} & Global warming $\left(C_{51}\right)$ & Negative & Quantitative \\
\hline & & Water eutrophication $\left(C_{52}\right)$ & Negative & Quantitative \\
\hline & & Acidizing $\left(C_{53}\right)$ & Negative & Quantitative \\
\hline & & Human toxicity $\left(C_{54}\right)$ & Negative & Quantitative \\
\hline
\end{tabular}

TABLE 5: The data of the environmental impact list.

\begin{tabular}{lcccccc}
\hline No. & Items & Unit & 2015 year & 2016 year & 2017 year & 2018 year \\
\hline 1 & Water resources quantity & $\times 10^{4} \mathrm{~m}$ & 753.25 & 548.99 & 537.11 & 492.59 \\
2 & Power & $\times 10^{4} \mathrm{Kwh} / \mathrm{a}$ & 610.48 & 556.76 & 518.18 & 932.72 \\
3 & Domestic sludge & $\mathrm{t} / \mathrm{a}$ & 268.32 & 201.83 & 234.15 & 97.55 \\
4 & $\mathrm{SS}$ & $\mathrm{t} / \mathrm{a}$ & 0.64 & 0.60 & 0.70 & 0.79 \\
5 & $\mathrm{COD}$ & $\mathrm{t} / \mathrm{a}$ & 97.50 & 34.45 & 30.38 & 34.76 \\
6 & $\mathrm{NH}_{3}-\mathrm{N}$ & $\mathrm{t} / \mathrm{a}$ & 4.07 & 1.42 & 2.56 & 1.84 \\
7 & $\mathrm{BOD}_{5}$ & $\mathrm{t} / \mathrm{a}$ & 43.04 & & 16.71 & 24.30 \\
\hline
\end{tabular}

landfill disposal of domestic sludge is estimated here. The data of the environmental impact list are shown in Table 5 [34].

4.1.2. Analysis of Driving Factors of Environmental Impact. According to the CML 2001 classification method, environ- mental impact potential values were calculated and shown in Table 6 [34]. The normalization results of environmental impact potential are shown in Table 7.

From Tables 6 and 7, it can be seen that the main sources of environmental impacts include power consumption, 
TABLE 6: Environmental impact potential values. PC: power consumption; DSL: domestic sludge landfill; STSD: sewage treatment station drainage.

\begin{tabular}{lccccccrrr}
\hline \multirow{2}{*}{ Type } & \multirow{2}{*}{ Unit } & PC & DSL & PC & DSL & PC & DSL & PC & DSL \\
\hline GWP & $\times 10^{6} \mathrm{kgCO}_{2}$ eq & 6.44 & 0.13 & 5.87 & 0.09 & 5.46 & 0.11 & 9.83 & 0.05 \\
AP & $\times 10^{4} \mathrm{kgSO}_{2}$ eq & 1.98 & $<0.01$ & 1.80 & $<0.01$ & 1.68 & $<0.01$ & 3.02 & $<0.01$ \\
HTP & $\times 10^{5} \mathrm{kgl}^{2}$-DCBeq & 2.13 & 0.12 & 1.94 & 0.09 & 1.81 & 0.10 & 3.26 & 0.04 \\
Type & Unit $_{\text {EP }}$ & STSD & DSL & STSD & DSL & STSD & DSL & STSD & DSL \\
EP & $\times 10^{4} \mathrm{kgPO}_{4}{ }^{3-}$ eq & 1.79 & $<0.01$ & 0.63 & $<0.01$ & 1.12 & $<0.01$ & 0.78 & $<0.01$ \\
\hline
\end{tabular}

TABLE 7: Normalization results of environmental impact potential values.

\begin{tabular}{lccccc}
\hline Type & 2015 & 2016 & 2017 & 2018 & Normalization value \\
\hline GWP & $1.58 E-07$ & $1.44 E-07$ & $1.34 E-07$ & $2.38 E-07$ & $4.15 E+13$ \\
AP & $5.91 E-08$ & $5.39 E-08$ & $5.02 E-08$ & $9.02 E-08$ & $3.35 E+11$ \\
EP & $1.36 E-07$ & $4.77 E-08$ & $8.49 E-08$ & $5.94 E-08$ & $1.32 E+11$ \\
HTP & $3.97 E-09$ & $3.59 E-09$ & $3.37 E-09$ & $5.82 E-09$ & $5.67 E+13$ \\
\hline
\end{tabular}

regional drainage, and landfill disposal of domestic sludge. Power consumption has the largest environmental impact, accounting for about $73 \%$, regional drainage accounts for about $26 \%$, and domestic sludge landfill accounts for about $1 \%$. The main influence types are global warming, acidification, eutrophication, and human toxicity. Global warming has the greatest impact potential, accounting for about $40 \%-60 \%$ of all types. The second is eutrophication and acidification, accounting for $15 \%-38 \%$ and $17 \%-23 \%$, respectively. The last is human toxicity, accounting for $1 \%$. Global warming, acidification, and human toxicity potential are highly synchronized with power consumption. From 2015 to 2017, these three environmental indicators gradually decreased. In 2018, with the increase of regional water consumption, the energy consumption of system operation also increased, leading to a significant influence on environment.

4.1.3. Resource Consumption List Analysis. The method described above was used for resource consumption list analysis. The results are shown in Table 8 [34].

4.1.4. Economic List Analysis. The saved water resource purchasing fee from 2015 to 2018 was 17.7563 million yuan, 27.2691 million yuan, 24.26300 million yuan, and 27.2831 million yuan respectively. The saved environmental protection tax was 0.37 million yuan, 0.59 million yuan, 0.44 million yuan, and 0.47 million yuan, respectively. Table 9 illustrates the calculated evaluation index values of economic list [34].

4.1.5. Technical Performance List Analysis. Table 10 shows the statistics of technical performance index of water treatment of the 5 sewage treatment stations [34]. The comprehensive statistical results of the technical performance indexes are shown in Table 11 [34].

4.1.6. Social Impact List Analysis. The social impact index values are shown in Table 12 [34].
4.2. Fusion Weight of List Indexes. First, the subjective and objective weights of evaluation indexes in above list analysis are determined by using the AHP method and CRITIC method respectively. Then, the subjective and objective weights are fused by game theory to obtain a balanced and coordinated fusion weight. The weights obtained by $\mathrm{AHP}, \mathrm{CRITIC}$, and game theory are represented by $\alpha, \beta$, and $\gamma$, respectively.

4.2.1. Subjective Weights by AHP. On the basis of above hierarchical evaluation model, the AHP method is used to make pairwise comparison and score the indexes by expert decision. $\alpha_{A-B}$ represents the weight of the criterion layer (layer $B$ ) to the target layer (layer $A$ ). The weight of index to the criterion layer and consistency check is shown in Table 13. It can be seen that the CR value of the consistency ratio of the judgment matrix is all less than 0.1 . The consistency test results meet the requirements.

Subjective weight of evaluation index layer (layer $C$ ) to target layer (layer $A$ ) is $\alpha_{\mathrm{A}-\mathrm{C}}=\{0.0909,0.0909,0.0909,0.0909$, $0.0165,0.0826,0.0826,0.0097,0.0766,0.0494,0.0231,0.0231$ $, 0.0130,0.0390,0.0390,0.0727,0.0364,0.0364,0.0364\}^{T}$.

4.2.2. Objective Weights by CRITIC. The CRITIC method is a method to deal with objective weight based on the variability and conflict among indicators. Standard deviation is used to reflect the degree of variation of data information. The larger the positive correlation coefficient of sample information, the smaller the conflict. The smaller the information difference of evaluation index, the smaller the weight of the index. In accordance with the measured data, CRITIC assigns different weights to the indexes without being affected by subjective factors. The specific calculation process of CRITIC method is shown in Appendix B 2.2.

By normalizing the original list data, the decision matrix of standardized evaluation indexes was obtained (Table 14). Then, the Pearson correlation coefficient and standard deviation among the evaluation indexes are solved (Tables 15 
TABLE 8: The value of water resource consumption index.

\begin{tabular}{|c|c|c|c|c|}
\hline Item & 2015 & 2016 & 2017 & 2018 \\
\hline Water utilization rate $(\%)$ & 60.61 & 68.85 & 61.28 & 65.00 \\
\hline Fresh water supply ratio (\%) & 62.31 & 44.74 & 46.35 & 41.34 \\
\hline Industrial water reuse rate (\%) & 37.69 & 55.26 & 53.65 & 58.66 \\
\hline Water consumption per ten thousand industrial added value $\left(\mathrm{m}^{3} / 10000\right.$ Yuan) & 21.05 & 23.15 & 18.21 & 16.11 \\
\hline
\end{tabular}

TABle 9: Evaluation index values of economic list.

\begin{tabular}{|c|c|c|c|c|}
\hline Item & 2015 & 2016 & 2017 & 2018 \\
\hline Resource acquisition cost (Yuan) & 2464.16 & 1799.49 & 1753.02 & 1524.56 \\
\hline Operating cost $\left(\right.$ Yuan $\left./ \mathrm{m}^{3}\right)$ & 2.39 & 2.24 & 2.18 & 2.77 \\
\hline Economic benefit (Yuan) & 1812.75 & 2786.09 & 2469.95 & 2774.82 \\
\hline
\end{tabular}

TABLE 10: Statistics of technical performance index of water treatment.

\begin{tabular}{|c|c|c|c|c|c|}
\hline Water treatment unit & Technical index & 2015 & 2016 & 2017 & 2018 \\
\hline \multirow{4}{*}{ Anjialing domestic sewage treatment station } & Average annual hydraulic load (\%) & 52 & 36 & 54 & 19 \\
\hline & Suspended matter removal amount (t/a) & 827.54 & 587.72 & 888.39 & 280.01 \\
\hline & COD removal amount $(\mathrm{t} / \mathrm{a})$ & 59.11 & 28.63 & 59.54 & 21.50 \\
\hline & $\mathrm{NH}_{3}-\mathrm{N}$ removal amount $(\mathrm{t} / \mathrm{a})$ & 3.77 & 2.53 & 3.77 & 1.16 \\
\hline \multirow{4}{*}{ Antaipo terminal sewage treatment station } & Average annual hydraulic load (\%) & 54 & 64 & 52 & 62 \\
\hline & Suspended matter removal amount ( $\mathrm{t} / \mathrm{a})$ & 371.10 & 453.40 & 361.66 & 385.16 \\
\hline & COD removal amount $(\mathrm{t} / \mathrm{a})$ & 28.16 & 26.62 & 22.43 & 25.43 \\
\hline & $\mathrm{NH}_{3}-\mathrm{N}$ removal amount $(\mathrm{t} / \mathrm{a})$ & 1.82 & 1.96 & 1.39 & 1.72 \\
\hline \multirow{4}{*}{$\begin{array}{l}\text { Underground water treatment station (No. A) of Jinggong } \\
\text { mine }\end{array}$} & Average annual hydraulic load (\%) & 102 & 42 & 56 & 14 \\
\hline & Suspended matter removal amount (t/a) & 8868.07 & 3078.89 & 4218.73 & 1079.44 \\
\hline & COD removal amount $(\mathrm{t} / \mathrm{a})$ & 187.60 & 63.85 & 96.87 & 25.77 \\
\hline & $\mathrm{NH}_{3}-\mathrm{N}$ removal amount $(\mathrm{t} / \mathrm{a})$ & 2.23 & 1.07 & 1.30 & 0.33 \\
\hline \multirow{4}{*}{$\begin{array}{l}\text { Underground water treatment station (No. B) of Jinggong } \\
\text { mine }\end{array}$} & Average annual hydraulic load (\%) & 23 & 25 & 29 & 39 \\
\hline & Suspended matter removal amount (t/a) & 3405.30 & 3874.25 & 4898.50 & 5252.58 \\
\hline & COD removal amount $(\mathrm{t} / \mathrm{a})$ & 67.85 & 64.49 & 68.65 & 101.45 \\
\hline & $\mathrm{NH}_{3}-\mathrm{N}$ removal amount $(\mathrm{t} / \mathrm{a})$ & 0.76 & 1.16 & 1.24 & 1.71 \\
\hline \multirow{4}{*}{ Anjialing terminal sewage treatment station } & Average annual hydraulic load (\%) & 107 & 98 & 92 & 89 \\
\hline & Suspended matter removal amount (t/a) & 8771.60 & 6005.00 & 5674.88 & 6183.61 \\
\hline & COD removal amount $(\mathrm{t} / \mathrm{a})$ & 224.56 & 209.77 & 183.21 & 189.63 \\
\hline & $\mathrm{NH}_{3}-\mathrm{N}$ removal amount $(\mathrm{t} / \mathrm{a})$ & 4.65 & 4.21 & 4.29 & 3.62 \\
\hline
\end{tabular}

TABLE 11: Technical performance index value.

\begin{tabular}{lcccc}
\hline Item & 2015 & 2016 & 2017 & 2018 \\
\hline Annual hydraulic load (\%) & 67 & 53 & 57 & 75 \\
Process stability (point) & 6 & 6 & 13999.26 & 16042.17 \\
Suspended matter removal amount (t/a) & 22243.61 & 393.36 & 430.71 & 13180.80 \\
COD removal amount (t/a) & 567.28 & 10.93 & 363.78 \\
$\mathrm{NH}_{3}$-N removal amount (t/a) & 13.23 & 8.55 \\
\hline
\end{tabular}


TABLe 12: Social impact index value.

\begin{tabular}{lcccc}
\hline Item & 2015 & 2016 & 2017 & 2018 \\
\hline Contribution to labor positions (unit) & 199 & 199 & 232 \\
Conformation to environmental regulations (point) & 7 & 7 & 89 & 8 \\
Perfection of management system (point) & 6 & 6 & 7 & 8 \\
\hline
\end{tabular}

TABLE 13: Weight of index to criterion layer and consistency check.

\begin{tabular}{|c|c|c|c|c|c|c|c|c|}
\hline Layer & & & Juds & natrix & & & Weight & Consistency check \\
\hline \multirow{6}{*}{$A-B$} & $A$ & $B_{1}$ & $B_{2}$ & $B_{3}$ & $B_{4}$ & $B_{5}$ & $\alpha_{A-B}$ & \multirow{6}{*}{$C R_{A-B}=0$} \\
\hline & $B_{1}$ & 1 & 2 & 2 & 4 & 2 & 0.3636 & \\
\hline & $B_{2}$ & 0.5 & 1 & 1 & 2 & 1 & 0.1818 & \\
\hline & $B_{3}$ & 0.5 & 1 & 1 & 2 & 1 & 0.1818 & \\
\hline & $B_{4}$ & 0.25 & 0.5 & 0.5 & 1 & 0.5 & 0.1818 & \\
\hline & $B_{5}$ & 0.5 & 1 & 1 & 2 & 1 & 0.0909 & \\
\hline \multirow{5}{*}{$B_{1}-C_{1}$} & $B_{1}$ & $C_{1}$ & $C_{2}$ & $C_{3}$ & $C_{4}$ & & $\alpha_{\mathrm{B} 1-\mathrm{C}}$ & \multirow{5}{*}{$C R_{B 1-C 1}=0$} \\
\hline & $C_{11}$ & 1 & 1 & 1 & 1 & & 0.2500 & \\
\hline & $C_{12}$ & 1 & 1 & 1 & 1 & & 0.2500 & \\
\hline & $C_{13}$ & 1 & 1 & 1 & 1 & & 0.2500 & \\
\hline & $C_{14}$ & 1 & 1 & 1 & 1 & & 0.2500 & \\
\hline \multirow{4}{*}{$B_{2}-C_{2}$} & $B_{2}$ & $C_{5}$ & $C_{6}$ & $C_{7}$ & & & $\alpha_{B 2-C}$ & \multirow{4}{*}{$C R_{B 2-C 2}=0$} \\
\hline & $C_{21}$ & 1 & 0.2 & 0.2 & & & 0.0909 & \\
\hline & $C_{22}$ & 5 & 1 & 1 & & & 0.4545 & \\
\hline & $C_{23}$ & 5 & 1 & 1 & & & 0.4545 & \\
\hline \multirow{6}{*}{$B_{3}-C_{3}$} & $B_{3}$ & $C_{8}$ & $C_{9}$ & $C_{10}$ & $C_{11}$ & $C_{12}$ & $\alpha_{B 3-C}$ & \multirow{6}{*}{$C R_{B 3-C 3}=0.0457$} \\
\hline & $C_{31}$ & 1 & 0.2 & 0.2 & 0.33 & 0.33 & 0.0535 & \\
\hline & $C_{32}$ & 5 & 1 & 3 & 3 & 3 & 0.4214 & \\
\hline & $C_{33}$ & 5 & 0.33 & 1 & 3 & 3 & 0.2715 & \\
\hline & $C_{34}$ & 3 & 0.33 & 0.33 & 1 & 1 & 0.1268 & \\
\hline & $C_{35}$ & 3 & 0.33 & 0.33 & 1 & 1 & 0.1268 & \\
\hline \multirow{4}{*}{$B_{4}-C_{4}$} & $B_{4}$ & $C_{13}$ & $C_{14}$ & $C_{15}$ & & & $\alpha_{B 4-C}$ & \multirow{4}{*}{$C R_{B 4-C 4}=0$} \\
\hline & $C_{43}$ & 1 & 0.33 & 0.33 & & & 0.1429 & \\
\hline & $C_{42}$ & 3 & 1 & 1 & & & 0.4286 & \\
\hline & $C_{41}$ & 3 & 1 & 1 & & & 0.4286 & \\
\hline \multirow{5}{*}{$B_{5}-C_{5}$} & $B_{5}$ & $C_{16}$ & $C_{17}$ & $C_{18}$ & $C_{19}$ & & $\alpha_{B 5-C}$ & \multirow{5}{*}{$C R_{B 5-C 5}=0$} \\
\hline & $C_{51}$ & 1 & 0.5 & 1 & 1 & & 0.4000 & \\
\hline & $C_{52}$ & 0.5 & 1 & 2 & 2 & & 0.2000 & \\
\hline & $C_{53}$ & 1 & 0.5 & 1 & 1 & & 0.2000 & \\
\hline & $C_{54}$ & 1 & 0.5 & 1 & 1 & & 0.2000 & \\
\hline
\end{tabular}

and 16). Finally, the objective weight is determined by CRITIC as shown in Table 17.

4.2.3. Fusion Weights by Game theory. According to the subjective weight and objective weight, the first-order derivative of optimization is carried out:

$$
\left[\begin{array}{ll}
0.0689 & 0.0519 \\
0.0519 & 0.0537
\end{array}\right]\left[\begin{array}{l}
\alpha_{1} \\
\alpha_{2}
\end{array}\right]=\left[\begin{array}{l}
0.0689 \\
0.0537
\end{array}\right]
$$

The linear combination coefficients $\alpha_{1}=0.9073$ and $\alpha_{2}=$ 0.1230 were calculated. The optimal weight vector combination 
TABle 14: Decision matrix of standardized evaluation indexes.

\begin{tabular}{lcccc}
\hline & 2015 & 2016 & 2017 & 2018 \\
\hline$C_{11}$ & 1.0000 & 0.0000 & 0.9180 & 0.4670 \\
$C_{12}$ & 0.0000 & 0.8376 & 0.7608 & 1.0000 \\
$C_{13}$ & 0.0000 & 0.8376 & 0.7608 & 1.0000 \\
$C_{14}$ & 0.3405 & 0.0000 & 0.7196 & 1.0000 \\
$C_{21}$ & 0.0000 & 0.7074 & 0.7569 & 1.0000 \\
$C_{22}$ & 0.6440 & 0.9071 & 1.0000 & 0.0000 \\
$C_{23}$ & 0.0000 & 1.0000 & 0.6752 & 0.9884 \\
$C_{31}$ & 0.0000 & 0.6398 & 0.4710 & 1.0000 \\
$C_{32}$ & 0.0000 & 0.0000 & 0.5000 & 1.0000 \\
$C_{33}$ & 1.0000 & 0.0903 & 0.3157 & 0.0000 \\
$C_{34}$ & 1.0000 & 0.1454 & 0.3289 & 0.0000 \\
$C_{35}$ & 1.0000 & 0.5096 & 0.7354 & 0.0000 \\
$C_{43}$ & 0.0000 & 0.0000 & 0.0000 & 1.0000 \\
$C_{42}$ & 0.0000 & 0.0000 & 0.5000 & 1.0000 \\
$C_{41}$ & 0.0000 & 0.0000 & 0.5000 & 1.0000 \\
$C_{51}$ & 0.7704 & 0.9091 & 1.0000 & 0.0000 \\
$C_{52}$ & 0.7769 & 0.9071 & 1.0000 & 0.0000 \\
$C_{53}$ & 0.0000 & 1.0000 & 0.5773 & 0.8672 \\
$C_{54}$ & 0.7554 & 0.9137 & 1.0000 & 0.0000 \\
\hline & & & &
\end{tabular}

coefficients $\alpha_{1}{ }^{*}=0.8806$ and $\alpha_{2}{ }^{*}=0.1194$ were obtained by normalizing $\alpha_{1}$ and $\alpha_{2}$. The game theory fusion weight of the evaluation index on the target layer is obtained as follows: $\gamma_{A-C}$ $=\alpha_{1}{ }^{*} \omega_{1}+\alpha_{2}{ }^{*} \omega_{2}=\{0.0870,0.0853,0.0853,0.0855,0.0195$, $0.0795,0.0785,0.0137,0.0733,0.0515,0.0281,0.0275,0.0183$, $0.0402,0.0402,0.0710,0.0391,0.0377,0.0390\}^{T}$.

In the same way, the game theory fusion weight value of the evaluation index for the rule layer is obtained: $\gamma_{B 1-C 1}=$ $\{0.3031,0.2295,0.2295,0.2379\}^{T}, \gamma_{\mathrm{B} 2-\mathrm{C} 2}=\{0.0355,0.4747$, $0.4897\}^{T}, \gamma_{B 3-C 3}=\{0.0610,0.4023,0.2687,0.1347,0.1332\}^{T}$, $\gamma_{B 4-C 4}=\{0.1841,0.4080,0.4080\}^{T}$, and $\gamma_{B 5-C 5}=\{0.4036,0.1983$, $0.1997,0.1984\}^{T}$.

4.3. Comprehensive Assessment of Water Resource Life Cycle Sustainability. The VIKOR method is a common and useful multicriteria decision-making technique that is used to determine a compromise alternative. The VIKOR method has the advantages of considering the maximization of group utility $\left(S_{i}\right)$, the minimization of individual regret $\left(R_{i}\right)$, and the subjective preferences of decision-makers and therefore has higher stability and credibility for ranking compared to other methods [35]. According to the calculation steps of CW-VIKOR in Appendix B, the fusion weight $\gamma$ was used to calculate the group utility value $S_{i}$, individual regret value $R_{i}$, and comprehensive utility value $Q_{i}$, respectively. Then, we sorted them by size. The smaller the $Q_{i}$ value is, the better the sustainable utilization of water resources in the life cycle.

\subsubsection{Evaluation Results of Each Subsystem}

(1) Comprehensive Evaluation of Resource Consumption. The positive and negative ideal solutions of resource consumption index are $P^{*}=(1,1,1,1)$ and $P^{-}=(0,0,0,0)$, respectively. The calculated $S_{i}, R_{i}$, and $Q_{i}$ value of the resource consumption subsystem is shown in Table 18.

The results show that the ranking result of $Q_{i}$ is 2017 $>2018>2015>2016$. The water utilization rate and water consumption per ten thousand industrial added value in 2016 were the highest, leading to low water utilization efficiency. The reason is that after 2016, the coal industry reduced the consumption of water resources; so, the regional water use efficiency increased from 2017 to 2018.

Although water use efficiency in the study area has been increasing in recent years, the reuse rate of industrial water is still low. There is still a large room for improvement. In general, the demand for fresh water used for production in the research area is gradually replaced by reclaimed water.

(2) Economic Comprehensive Evaluation. The positive and negative ideal solutions of the economic index are $P^{*}=$ $(1,1,1)$ and $P^{-}=(0,0,0)$ respectively. The calculated $S_{i}$, $R_{i}$, and $Q_{i}$ value of the economic subsystem is shown in Table 19.

The results show that the ranking result of $Q_{i}$ is 2016 $>2017>2018>2015$. From 2016 to 2017, their $Q_{i}$ values are relatively low, which is due to the relatively low operating cost of the system. Meanwhile, the saved water resource purchasing fee and the saved environmental protection tax by water reuse project have relatively high contribution to economic benefits. In 2018, in order to improve the stability of the operation system, the coal enterprise increased the investment for the operation and maintenance of the water system. The labor cost, material cost, and business contract fee also increased. So, the operation cost increased.

(3) Comprehensive Evaluation of Technical Performance. The positive and negative ideal solutions of the technical performance index are $P^{*}=(1,1,1,1)$ and $P^{-}=(0,0,0,0)$, respectively. The calculated $S_{i}, R_{i}$, and $Q_{i}$ value of the technical performance subsystem is shown in Table 20.

The results show that the ranking result of $Q_{i}$ is 2017 $>2018>2015>2016$. From 2017 to 2018 , their $Q_{i}$ values were relatively low, and the water system operated stably. While in 2016, the system operated in a relatively poor state. The manifestation is the serious siltation of coal slime in the presettling adjusting tank. The main reason is that Anjialing Terminal sewage treatment station has frequently appeared problems since November 2015. The underground water treatment system (No. B) of Jinggong No.1 Mine is unable to discharge mud due to the high suspended matter, which affects the operation and the water quality of the effluent. After 2017, with the decrease of coal production capacity and the well closure of Jinggong No.2 Mine, the amount of waste water generated by regional production decreases. 


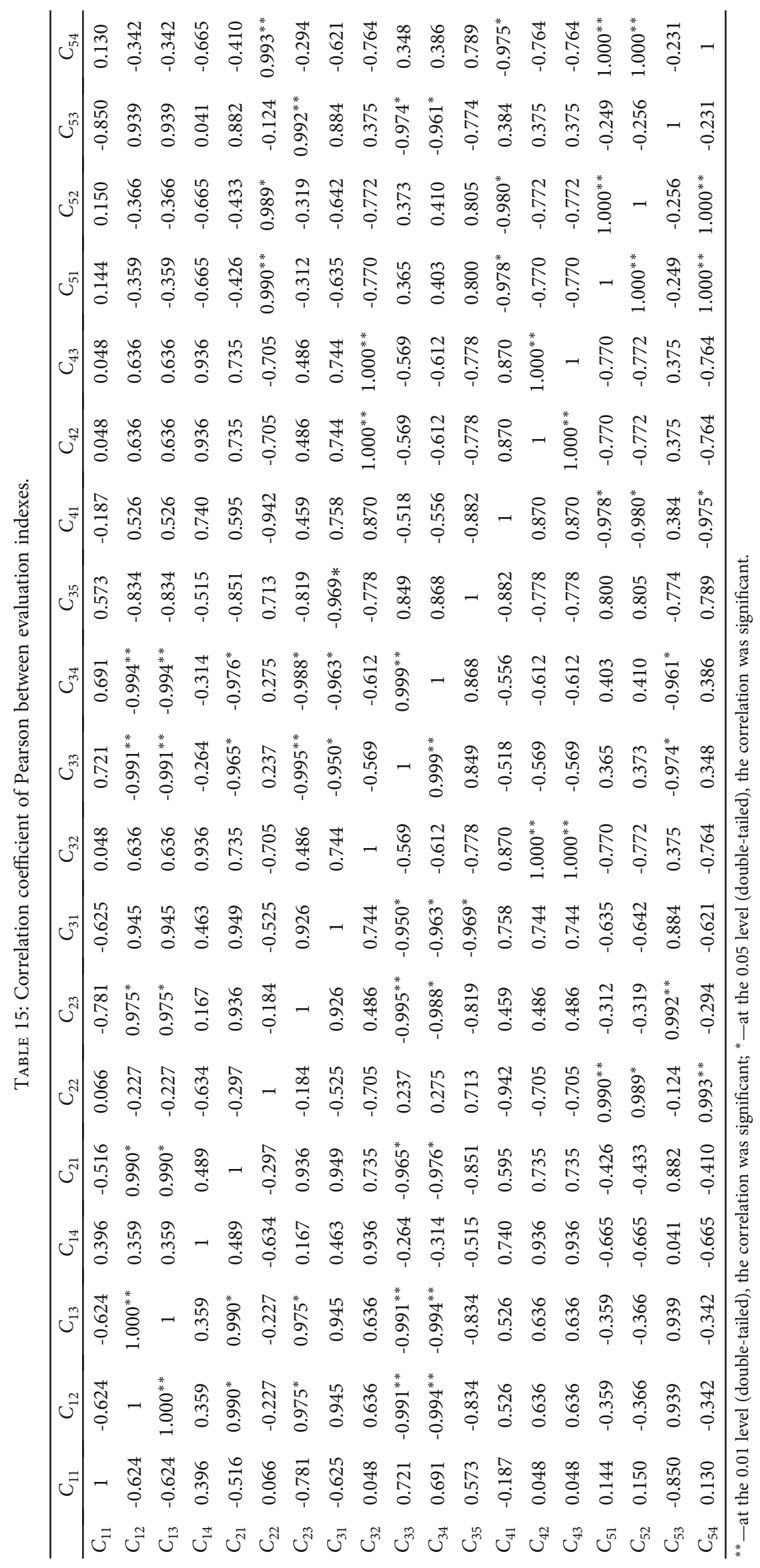


TABLE 16: Standard deviation between evaluation indexes.

\begin{tabular}{lcccccccccc}
\hline Index & $C_{11}$ & $C_{12}$ & $C_{13}$ & $C_{14}$ & $C_{21}$ & $C_{22}$ & $C_{23}$ & $C_{31}$ & $C_{32}$ & $C_{33}$ \\
\hline Standard deviation & 0.46 & 0.44 & 0.44 & 0.44 & 0.43 & 0.45 & 0.47 & 0.42 & 0.48 & 0.45 \\
Index & $C_{34}$ & $C_{35}$ & $C_{41}$ & $C_{42}$ & $C_{43}$ & $C_{51}$ & $C_{52}$ & $C_{53}$ & $C_{54}$ & \\
Standard deviation & 0.44 & 0.42 & 0.50 & 0.48 & 0.48 & 0.46 & 0.46 & 0.44 & 0.46 \\
\hline
\end{tabular}

TABLE 17: Weight of evaluation indexes.

\begin{tabular}{|c|c|c|c|c|}
\hline Target layer $(A)$ & Rule layer $(B)$ & Index layer $(C)$ & $\beta_{B-C}$ & $\beta_{A-C}$ \\
\hline \multirow{19}{*}{ Water life cycle sustainability } & \multirow{4}{*}{ Resource consumption $(0.1917)$} & Water utilization rate $\left(C_{11}\right)$ & 0.3031 & 0.0581 \\
\hline & & Fresh water supply ratio $\left(C_{12}\right)$ & 0.2295 & 0.0440 \\
\hline & & $\begin{array}{l}\text { Water consumption per ten thousand industrial } \\
\text { added value }\left(C_{13}\right)\end{array}$ & 0.2295 & 0.0440 \\
\hline & & Industrial water reuse rate $\left(C_{14}\right)$ & 0.2379 & 0.0456 \\
\hline & \multirow{3}{*}{ Economy $(0.1468)$} & Resource acquisition cost $\left(C_{21}\right)$ & 0.2854 & 0.0419 \\
\hline & & Operating cost $\left(C_{22}\right)$ & 0.3835 & 0.0563 \\
\hline & & Economic benefit $\left(C_{23}\right)$ & 0.3311 & 0.0486 \\
\hline & \multirow{5}{*}{ Technical performance $(0.2836)$} & Average annual hydraulic load $\left(C_{31}\right)$ & 0.1520 & 0.0431 \\
\hline & & Process stability $\left(C_{32}\right)$ & 0.1717 & 0.0487 \\
\hline & & Suspended matter removal amount $\left(C_{33}\right)$ & 0.2352 & 0.0667 \\
\hline & & COD removal amount $\left(C_{34}\right)$ & 0.2306 & 0.0654 \\
\hline & & $\mathrm{NH}_{3}-\mathrm{N}$ removal amount $\left(C_{35}\right)$ & 0.2105 & 0.0597 \\
\hline & \multirow{3}{*}{ Social impact $(0.1546)$} & Contribution to Labor Position $\left(C_{41}\right)$ & 0.3700 & 0.0572 \\
\hline & & Conformation to environmental regulations $\left(C_{42}\right)$ & 0.3150 & 0.0487 \\
\hline & & Perfection of the management system $\left(C_{43}\right)$ & 0.3150 & 0.0487 \\
\hline & \multirow{4}{*}{ Environmental impact (0.2233) } & Global warming $\left(C_{51}\right)$ & 0.2629 & 0.0587 \\
\hline & & Water eutrophication $\left(C_{52}\right)$ & 0.2633 & 0.0588 \\
\hline & & Acidification $\left(C_{53}\right)$ & 0.2118 & 0.0473 \\
\hline & & Human toxicity $\left(C_{54}\right)$ & 0.2620 & 0.0585 \\
\hline
\end{tabular}

TABle 18: $S_{i}, R_{i}$, and $Q_{i}$ value of the resource consumption subsystem.

\begin{tabular}{ccccccc}
\hline Year & $S_{i}$ & Rank & $R_{i}$ & Rank & $Q_{i}$ & Rank \\
\hline 2015 & 0.6159 & 4 & 0.2295 & 3 & 0.8443 & 3 \\
2016 & 0.6155 & 3 & 0.3031 & 4 & 0.9996 & 4 \\
2017 & 0.2014 & 2 & 0.0667 & 1 & 0.0438 & 1 \\
2018 & 0.1616 & 1 & 0.1616 & 2 & 0.2006 & 2 \\
\hline
\end{tabular}

TABle 19: $S_{i}, R_{i}$, and $Q_{i}$ value of economic subsystem.

\begin{tabular}{ccccccc}
\hline Year & $S_{i}$ & Rank & $R_{i}$ & Rank & $Q_{i}$ & Rank \\
\hline 2015 & 0.6942 & 4 & 0.4897 & 4 & 1.0000 & 4 \\
2016 & 0.0545 & 1 & 0.0441 & 1 & 0.0000 & 1 \\
2017 & 0.1677 & 2 & 0.1591 & 2 & 0.2174 & 2 \\
2018 & 0.4804 & 3 & 0.4747 & 3 & 0.8160 & 3 \\
\hline
\end{tabular}

Therefore, the removal of pollutants decreases, and the $Q_{i}$ value of the technical subsystem decreases accordingly.

The treatment of domestic sewage in the mining area is relatively stable while the treatment of industrial and underground sewage is relatively complex. The removal rate of
TABLE 20: $S_{i}, R_{i}$, and $Q_{i}$ value of technical performance subsystem.

\begin{tabular}{ccccccc}
\hline Year & $S_{i}$ & Rank & $R_{i}$ & Rank & $Q_{i}$ & Rank \\
\hline 2015 & 0.4633 & 3 & 0.4023 & 3 & 0.5000 & 3 \\
2016 & 0.8491 & 4 & 0.4023 & 4 & 1.0000 & 4 \\
2017 & 0.5429 & 2 & 0.2012 & 1 & 0.1032 & 1 \\
2018 & 0.5366 & 1 & 0.2687 & 2 & 0.2629 & 2 \\
\hline
\end{tabular}

suspended matter in underground water treatment station is high, but the process stability is poor. The reason is that the content of suspended matter in the influent is high and unstable. The annual hydraulic load of Anjialing terminal sewage treatment station is high, and the sewage source is relatively complex.

(4) Comprehensive Evaluation of Social Impact. The positive and negative ideal solutions of the social impact index are $P^{*}=(1,1,1)$ and $P^{-}=(0,0,0)$, respectively. The calculated $S_{i}, R_{i}$, and $Q_{i}$ value of the social impact subsystem is shown in Table 21.

The results show that the ranking result of $Q_{i}$ is 2018 $>2017>2016>2015$. The overall social impact of the 
TABLE 21: $S_{i}, R_{i}$, and $Q_{i}$ value of the social impact subsystem.

\begin{tabular}{ccccccc}
\hline Year & $S_{i}$ & Rank & $R_{i}$ & Rank & $Q_{i}$ & Rank \\
\hline 2015 & 1.0001 & 4 & 0.4080 & 4 & 1.0000 & 4 \\
2016 & 1.0001 & 3 & 0.4080 & 3 & 1.0000 & 3 \\
2017 & 0.5921 & 2 & 0.2040 & 2 & 0.5460 & 2 \\
2018 & 0.0000 & 1 & 0.0000 & 1 & 0.0000 & 1 \\
\hline
\end{tabular}

system continues to improve. The perspective of social impact, perfection of the management system, and conformation to environmental regulations all have a significant impact on social subsystems.

From 2017 to 2018, the coal industry has successively designed the Anjialing Regional Sewage Treatment System Upgrading and Emissions Reduction Project. The industry also implemented technical transformation and optimization projects for the water supply and drainage system. It improved the system management system and the regional environmental supervision mechanism. These measures fully increased the employment opportunities.

(5) Comprehensive Evaluation of Environmental Impact. The positive and negative ideal solutions of the environmental impact index are $P^{*}=(1,1,1,1)$ and $P^{-}=(0,0,0,0)$, respectively. The calculated $S_{i}, R_{i}$, and $Q_{i}$ value of the environmental impact subsystem is shown in Table 22.

The results show that the ranking result of $Q_{i}$ is 2016 $>2017>2015>2018$. In 2018, with the increase of system operating load and a large amount of energy input, the contribution of potential value of global warming, acidification, and human toxicity increased significantly, leading to a significant decline in the sustainability of the environmental subsystem. More than $97 \%$ of the global warming potential and $99 \%$ of the acidification potential of the system increase with power consumption. The potential of global warming and acidification can be effectively reduced by reducing system power consumption. The reuse of reclaimed water can also reduce the impact on the environment. The greater the reuse of water, the smaller the eutrophication potential. Although the environmental impact potential value of systemic domestic sludge landfill is smaller than that of other influencing factors, many studies have shown that sludge landfill is not an environmentally friendly disposal method, and enterprises should seek a relatively harmless disposal scheme.

4.3.2. Systematic Comprehensive Evaluation Results. According to the CW-VIKOR evaluation model, the calculated $S_{i}$, $R_{i}$, and $Q_{i}$ value of water resource life cycle sustainability is shown in Table 23 and Figure 3.

The results show that the ranking result of $Q_{i}$ is 2017 $>2018>2016>2015$. During the research period, the $Q_{i}$ value showed a decreasing trend, indicating that the sustainability of regional water resource life cycle was improved.

In 2015, the sustainability of water resource life cycle performed poorly in three aspects: economic subsystem, social
TABLE 22: $S_{i}, R_{i}$, and $Q_{i}$ value of environmental impact subsystem.

\begin{tabular}{ccccccc}
\hline Year & $S_{i}$ & Rank & $R_{i}$ & Rank & $Q_{i}$ & Rank \\
\hline 2015 & 0.3852 & 3 & 0.1997 & 3 & 0.4295 & 3 \\
2016 & 0.0723 & 1 & 0.0367 & 1 & 0.0000 & 1 \\
2017 & 0.0844 & 2 & 0.0844 & 2 & 0.0731 & 2 \\
2018 & 0.8268 & 4 & 0.4036 & 4 & 1.0000 & 4 \\
\hline
\end{tabular}

TABLe 23: $S_{i}, R_{i}$, and $Q_{i}$ value of water resource life cycle sustainability.

\begin{tabular}{ccccccc}
\hline Year & $S_{i}$ & Rank & $R_{i}$ & Rank & $Q_{i}$ & Rank \\
\hline 2015 & 0.6112 & 4 & 0.0853 & 3 & 0.9833 & 4 \\
2016 & 0.4879 & 3 & 0.0870 & 4 & 0.8128 & 3 \\
2017 & 0.2818 & 1 & 0.0366 & 1 & 0.0000 & 1 \\
2018 & 0.3880 & 2 & 0.0795 & 2 & 0.5865 & 2 \\
\hline
\end{tabular}

subsystem, and resource subsystem. In terms of resource consumption, fresh water accounted for a higher proportion of water supply (about 62.31\%), while industrial water reuse rate was low (only $37.69 \%$ ). On the economic side, there is less economic benefit, mainly because only a small portion of reclaimed water is returned to production water.

In 2016, the sustainability of water resources life cycle is restricted by society, technology, and resources. The water utilization rate and water consumption of ten thousand Yuan of industrial added value in this year are the main influencing indexes. Another important influence is the poor process stability. The sewage treatment system of Anjialing terminal sewage treatment station often cannot operate normally, affecting the effluent quality effect.

In 2017 , the sustainability of the regional water resource life cycle was relatively strong, but there was still a large room for progress. For example, the water utilization efficiency was far from the domestic advanced level, and a large amount of recycled water was not effectively used.

In 2018, social subsystems performed well, with more professional management models, clearer functional division of labor, and improved work efficiency. With the increase of regional water consumption, operating cost, and energy consumption, the evaluation value of the environmental subsystem and economic subsystem increased obviously. In fact, energy saving and consumption reduction is an effective way to alleviate the contradiction between the increase of water quantity in operation and the increase of pollutant discharge.

4.4. Optimization Strategy. Based on above dynamic evaluation results, optimization strategy for continuous improvement is suggested as follows:

(1) Continuously improve the water resources management mode. Adjusting industrial structure and adopting water-saving facilities can reduce the demand for fresh water and improve water use efficiency

(2) Continuously improve the quality treatment and quality supply of wastewater. According to the different 


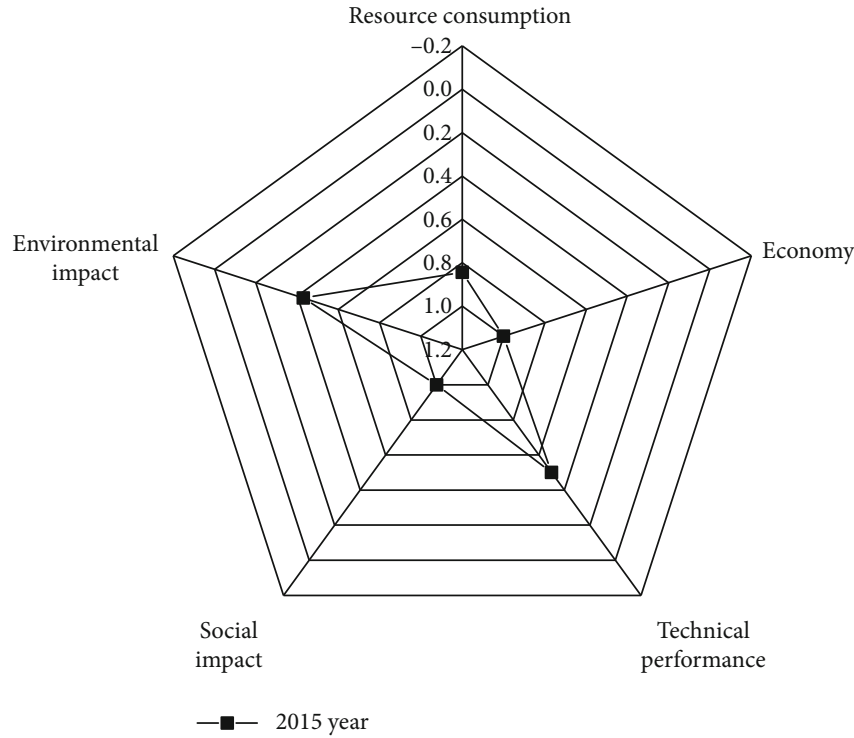

(a)

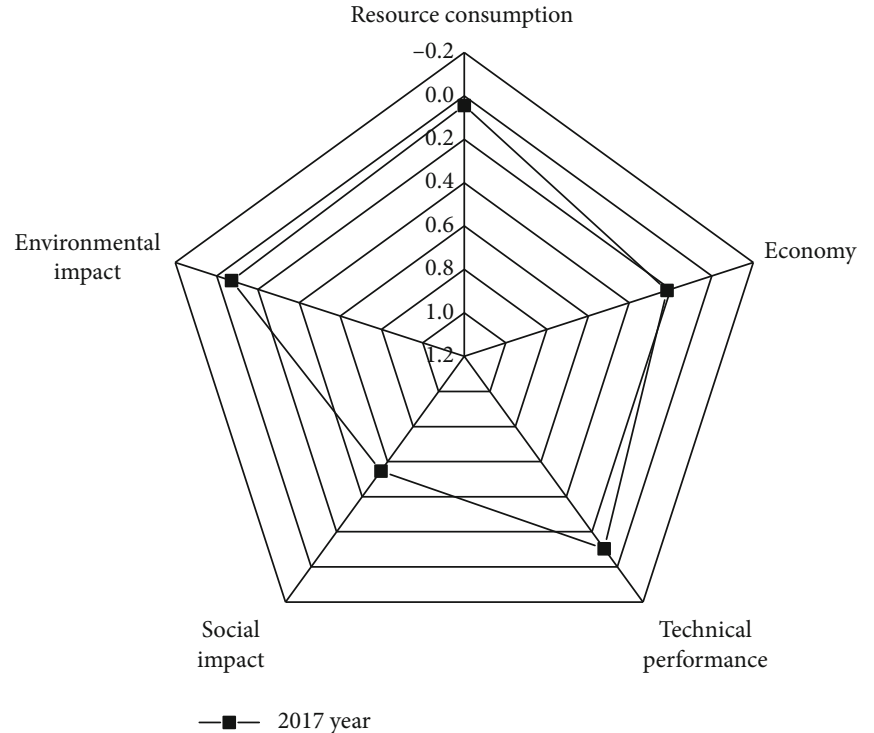

(c)

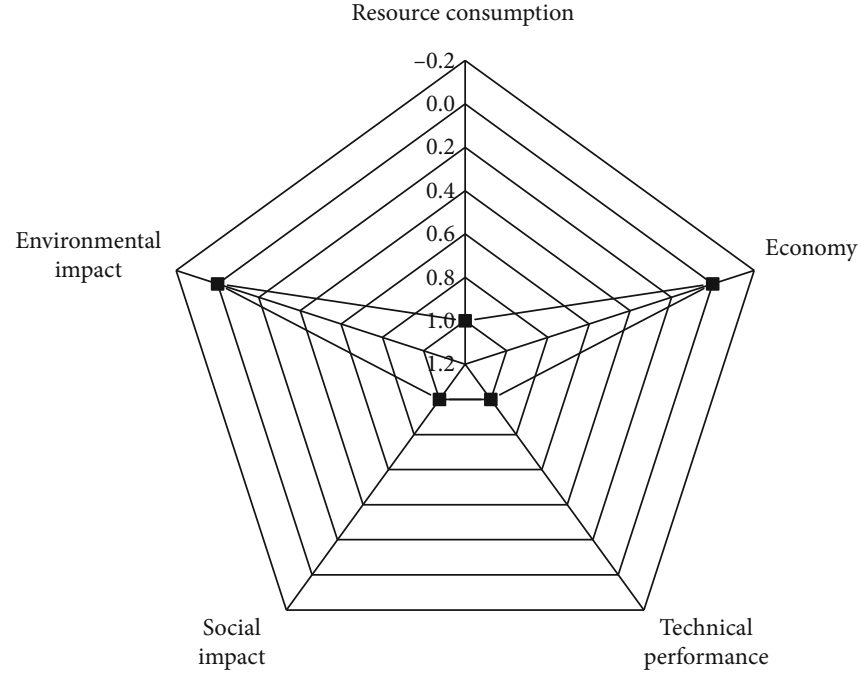

- - 2016 year

(b)

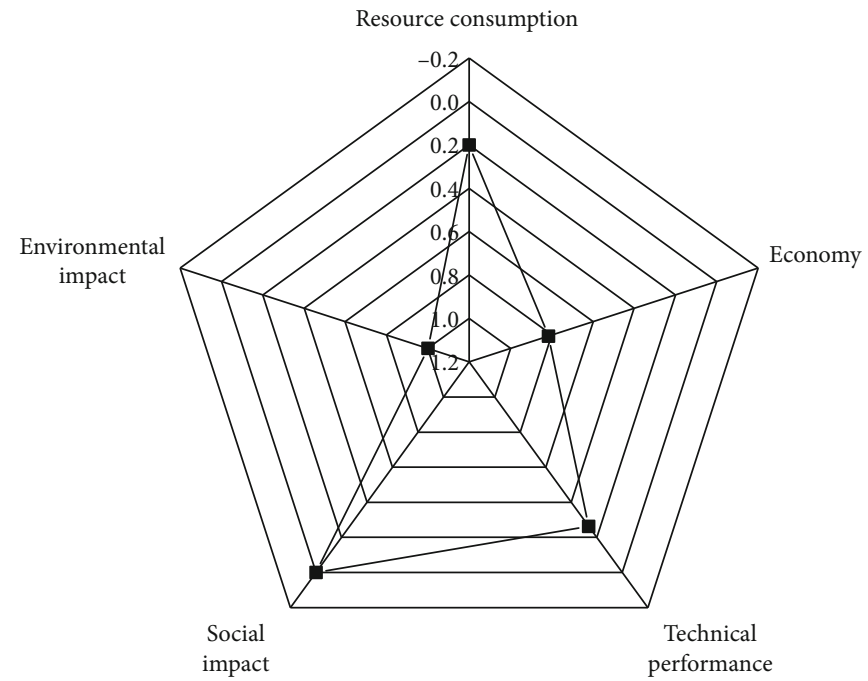

-a- 2018 year

Figure 3: Continued. 


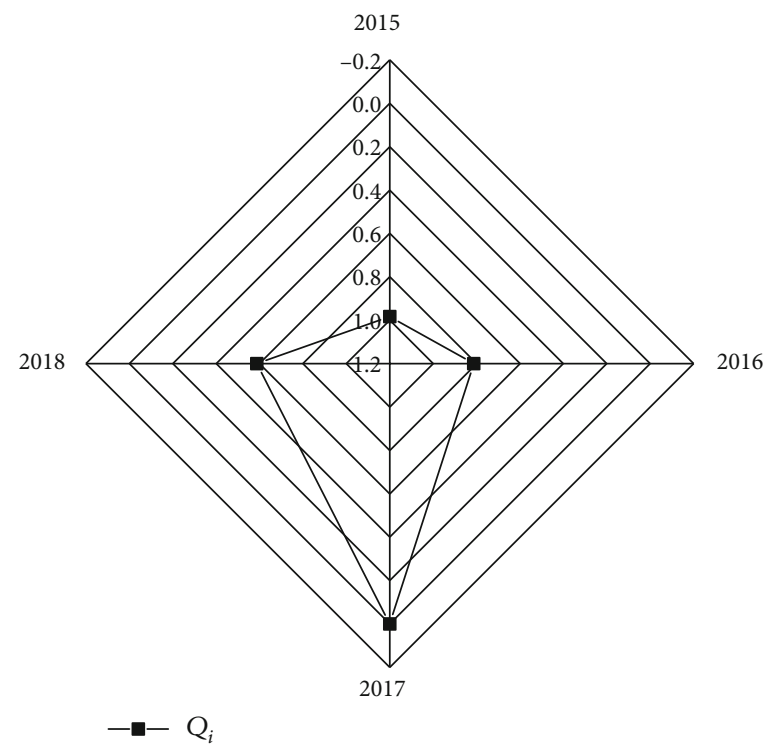

(e)

Figure 3: Comprehensive assessment results of water resource life cycle sustainability.

water quality requirements of different water subsystems, water users with high water quality in the upstream should be given priority. Meanwhile, water drainage should be directly supplied to water users with low water quality in the downstream. Implement the fine management of wastewater treatment and supply, reduce the input of sewage treatment system, and reuse the drainage without treatment

(3) Continuously improve the stability of sewage treatment process. First, the source control should be carried out to reduce the concentration of suspended matter in the sewage treatment station. Second, solve the problems in the coal slime pressure and filtration of the underground water treatment station (No. B) of Jinggong No.1 mine as soon as possible. For the drainage of coal preparation plant, the closedcircuit circulation should be enhanced, and the washing intensity should be strictly controlled. Then, the serious siltation of water diversion culvert and presedimentation regulating tank should be regularly cleaned. Finally, the dredging pump should be replaced to improve the slime discharging capacity

(4) Continue to save energy and reduce power consumption and costs

\section{Conclusions}

In this paper, a dynamic model was established to evaluate the water utilization efficiency in the coal mining area based on the life cycle sustainability assessment theory. The influence of five aspects (including resources, economy, technology, society, and environment) and 19 factors was considered. The game theory method was adopted to calculate the fusion weights. The CW-VIKOR method was used to explain the dynamic evaluation results of water efficiency in the coal mining area. The main conclusions are listed as follows:

(1) For the water resource utilization in mining area, the environmental impact mainly comes from three aspects: regional drainage, domestic sludge landfill and disposal, and water system operation power consumption. Power consumption has the greatest environmental impact, accounting for about $73 \%$, regional drainage for about $26 \%$, and domestic sludge landfill for about $1 \%$

(2) The CW-VIKOR method can coordinate the relationships among resource consumption, economy, technical performance, social impact, and environmental impact. The evaluation result is reliable and close to the actual situation

(3) From 2015 to 2018, the comprehensive utility value of water resource life cycle sustainability in the mining area was $0.983,0.813,0.000$, and 0.587 , respectively. It indicates that the water resource life cycle sustainability ranked first in 2017 and was relatively low in 2015. It can be seen that the sustainability of water resources life cycle in this mine area has improved as a whole

(4) More than $97 \%$ of the global warming potential and $99 \%$ of the acidification potential of the system increase with power consumption. The potential of global warming and acidification can be effectively reduced by reducing system power consumption. The reuse of reclaimed water can also reduce the impact on the environment. The greater the reuse of water, the smaller the eutrophication potential

The dynamic model established in this paper is also applicable to other coal mine areas, and only the factor 
weights need to be modified according to the specific characteristics of each coal mine. It can provide guidance for optimal exploitation and allocation of coal mine water resources.

\section{Appendix}

A.

\section{A.1. Characteristics of Environmental Impact}

(1) Global Warming

Emissions of greenhouse gases such as $\mathrm{CO}_{2}, \mathrm{~N}_{2} \mathrm{O}$, and $\mathrm{CH}_{4}$ increase the greenhouse effect. The global warming potential value was obtained by using equivalent coefficient method and taking $\mathrm{CO}_{2}$ equivalent as reference

$$
\mathrm{GWP}=\sum_{i} \delta_{i} \times M_{\mathrm{GWP}}
$$

where GWP denotes global warming potential $\left(\mathrm{kgCO}_{2} \mathrm{eq}\right) . \delta_{i}$ denotes the global warming potential coefficient of greenhouse gas $i\left(\mathrm{kgCO}_{2} \mathrm{eq} / \mathrm{kg}\right) . M_{\mathrm{GWP}}$ denotes emission mass of greenhouse gas $i(\mathrm{~kg})$. The potential coefficient of GWP is shown in Table 24.

\section{(2) Acidification}

The acidification potential was obtained by converting the pollutants with the equivalent of $\mathrm{SO}_{2}$ as reference.

$$
\mathrm{AP}=\sum_{i} \varepsilon_{i} \times M_{\mathrm{AP}}
$$

where AP denotes acidification potential $\left(\mathrm{kgSO}_{2} \mathrm{eq}\right) . \varepsilon_{i}$ denotes the acidification potential coefficient of pollutant $i$ ( $\left.\mathrm{kgSO}_{2} \mathrm{eq} / \mathrm{kg}\right) . M_{\mathrm{AP}}$ denotes the discharge mass of acidified pollutant $i(\mathrm{~kg})$. The $A P$ potential coefficient is shown in Table 25.

\section{(3) Eutrophication}

The eutrophication potential value was obtained by conversion with $\mathrm{PO}_{4}{ }^{3-}$ equivalent as reference.

$$
\mathrm{EP}=\sum_{i} \lambda_{i} \times M_{\mathrm{EP}}
$$

where EP denotes eutrophication potential value ( $\left.\mathrm{kgPO}_{4}{ }^{3-} \mathrm{eq}\right) . \lambda_{i}$ denotes eutrophication potential coefficient $\left(\mathrm{kgPO}_{4}{ }^{3-} \mathrm{eq} / \mathrm{kg}\right) . M_{\mathrm{EP}}$ denotes discharge mass of pollutant $i$ (kg). The EP potential coefficient is shown in Table 26.

\section{(4) Human Toxicity}

All potential contaminants that are toxic to humans are converted with 1,4-dichlorobenzene equivalent as a reference.

$$
\mathrm{HTP}=\sum_{i} \beta_{i} \times M_{\mathrm{HTP}}
$$

where HTP denotes human toxicity potential value $(\mathrm{kg}) ; \beta_{i}$ denotes human toxicity impact potential coefficient (kg1, 4-DCBeq $/ \mathrm{kg}$ ). $M_{\mathrm{HTP}}$ denotes discharge mass of toxic pollutant $i(\mathrm{~kg})$. The potential coefficient of HTP is shown in Table 27.

A.2. Standardization of Environmental Impact Indexes. In order to compare the impact results of different types of environment during the operation of water systems, the characteristic results need to be normalized. The standardized calculation formula is shown as (A.4) and (A.5).

$$
N_{i}=\frac{C_{i}}{S_{i}}
$$

where $N_{\mathrm{i}}$ denotes the standardization result of index. $C_{\mathrm{i}}$ denotes the characteristic result of index. $S_{i}$ denotes the standardization base value. The standard reference values in the CML 2001 method were adopted (Table 28).

\section{B.}

B.1. Data Standardization. In order to eliminate dimensionless inconsistency of variables, the range normalization method is used for processing, so as to obtain the standardized decision matrix $Y=\left[y_{i j}\right]_{m \times n}$. The calculation formula of standardized data, $y_{i j}$, is as follows:

For positive index,

$$
y_{i j}=\frac{\left(x_{i j}-x_{i j}^{\min }\right)}{\left(x_{i j}^{\max }-x_{i j}^{\min }\right)} .
$$

For reverse index,

$$
y_{i j}=\frac{\left(x_{i j}^{\max }-x_{i j}\right)}{\left(x_{i j}^{\max }-x_{i j}^{\min }\right)},
$$

where $y_{i j}$ is the normalized data of index $j$ in scheme $i . y_{i j}$ is the original data of index $j$ in scheme $i . x_{i j}^{x_{i j}^{\max }}$ and $x_{i j}^{\min }$ are respectively the maximum and minimum value of the original value of the evaluation index $j$.

B.2. Determination of Fusion Weight. In this paper, first, the analytic hierarchy process (AHP) and CRITIC method are respectively used to calculate the weight of each index in the evaluation system of water resources in the mining area. Then, the final fusion weight is determined according to the game theory method. The specific methods are as follows.

B.2.1. Weight by AHP. The order of importance of the evaluation factors was pairwise compared by the expert advisory group to establish the judgment matrix $A$. After quantization, check the consistency of matrix $A$. The application steps of this method are as follows: 
TABLE 24: GWP pollutant and potential coefficient.

\begin{tabular}{lcccc}
\hline Pollutant & $\mathrm{CO}_{2}$ & $\mathrm{CH}_{4}$ & $\mathrm{~N}_{2} \mathrm{O}$ & \\
\hline Potential coefficient & 1 & 28 & 265 & 0.027 \\
\hline
\end{tabular}

TABLE 25: AP pollutants and potential coefficients.

\begin{tabular}{lccc}
\hline Pollutant & $\mathrm{SO}_{2}$ & $\mathrm{NO}_{\mathrm{X}}$ & $\mathrm{NH}_{3}$ \\
\hline Potential coefficient & 1 & 0.5 & 1.6 \\
\hline
\end{tabular}

TABLE 26: EP pollutant and potential coefficient.

\begin{tabular}{|c|c|c|c|c|c|}
\hline Pollutant & COD & $\mathrm{NH}_{3}-\mathrm{N}$ & $\mathrm{BOD}_{5}$ & $\mathrm{TP}$ & $\mathrm{TN}$ \\
\hline Potential coefficient & 0.022 & 3.64 & 0.022 & 3.06 & 0.42 \\
\hline
\end{tabular}

TABLE 27: HTP pollutant and potential coefficient.

\begin{tabular}{lcccccccccc}
\hline Air pollutant & \multicolumn{2}{c}{$\mathrm{CO}$} & \multicolumn{3}{c}{$\mathrm{NH}_{3}$} & & $\mathrm{NO}_{\mathrm{X}}$ & & \multicolumn{2}{c}{$\mathrm{PM} 10$} \\
\hline Potential coefficient & \multicolumn{2}{c}{0.012} & \multicolumn{3}{c}{0.1} & & 1.2 & & \multicolumn{2}{c}{0.82} \\
Water pollutant & $\mathrm{Hg}$ & $\mathrm{Pb}$ & $\mathrm{Cd}$ & $\mathrm{Ni}$ & $\mathrm{Zn}$ & $\mathrm{Cu}$ & $\mathrm{Cr}$ & $\mathrm{Sn}$ & $\mathrm{As}$ & $\mathrm{Se}$ \\
Potential coefficient & 1425.6 & 12.26 & 22.89 & 331.08 & 0.58 & 1.34 & 3.42 & 0.017 & 951 & 56011 \\
Soil pollutant & $\mathrm{Hg}$ & $\mathrm{Pb}$ & $\mathrm{Cd}$ & $\mathrm{Ni}$ & $\mathrm{Zn}$ & $\mathrm{Cu}$ & $\mathrm{Cr}$ & $\mathrm{Sn}$ & \\
Potential coefficient & 1080.54 & 293.3 & 66.68 & 198.17 & 0.42 & 1.25 & 500 & 0.52 & \\
\hline
\end{tabular}

TABle 28: Normalization reference value of CML 2001.

\begin{tabular}{lcc}
\hline Impact type & $\begin{array}{c}\text { Standardization base } \\
\text { value }\end{array}$ & Unit \\
\hline $\begin{array}{l}\text { Climate change } \\
\text { (GWP100a) }\end{array}$ & $4.15 E+13$ & $\mathrm{kgCO}_{2} \mathrm{eq}$ \\
Acidification potential & $3.35 E+11$ & $\mathrm{kgSO}_{2} \mathrm{eq}$ \\
$\begin{array}{l}\text { Eutrophication potential } \\
\begin{array}{l}\text { Human toxicity } \\
\text { (HTP100a) }\end{array}\end{array}$ & $1.32 E+11$ & $\mathrm{kgPO}_{4} \mathrm{eq}$ \\
& $5.67 E+13$ & $\mathrm{~kg} 1,4-^{-}$ \\
\hline
\end{tabular}

(1) Construction of Judgment Matrix

An $n$-order matrix $A$ containing $n$ evaluation indexes is constituted:

$$
A=\left[\begin{array}{ccc}
a_{11} & \cdots & a_{1 n} \\
\vdots & & \vdots \\
a_{n 1} & \cdots & a_{n n}
\end{array}\right] .
$$

The scale and meaning of the judgment matrix are shown in Table 29.

\section{(2) Weight Vector}

The maximum eigenvalue and eigenvector of the matrix are calculated according to the established judgment matrix.
In this paper, the root method is adopted to calculate the component of the eigenvector, namely, the weight value $W$.

Calculate the component vectors $\bar{M}_{i}$ of the eigenvectors $W_{i}$ of matrix $A$

$$
\overline{M_{i}}=\left[\prod_{i=1}^{n} a_{i j}\right]^{\frac{1}{n}}(i, j=1,2, \cdots, n) .
$$

Normalization of $\bar{M}_{i}$ will be carried out to obtain the weight vector $W_{i}$

$$
W_{i}=\frac{\overline{M_{i}}}{\sum_{i=1}^{n} \bar{M}_{i}}(i=1,2, \cdots, n) .
$$

The maximum eigenroot value $\lambda_{\max }$ is calculated according to $W_{\mathrm{i}}$ and $A$

$$
\lambda_{\max }=\frac{1}{n} \sum_{i=1}^{n} \frac{(A W)_{i}}{W_{i}}
$$

\section{(3) Consistency Check}

Hierarchy sorting consistency test was carried out. The verification coefficient $\mathrm{CR}$ was calculated by using the 
TABLE 29: Judge the scale and meaning of the matrix.

\begin{tabular}{lc}
\hline Scale & Meaning \\
\hline 1 & Both factors are equally important \\
3 & The former is slightly more important than the latter \\
5 & The former is more important than the latter \\
7 & The former is much more important than the latter \\
9 & The former is extremely important than the latter \\
$2,4,6,8$ & The median of the above adjacent judgments \\
\hline
\end{tabular}

average random consistency index $\mathrm{RI}$ (Table 30)

$$
\mathrm{CR}=\frac{\mathrm{CI}}{\mathrm{RI}}=\frac{\lambda_{\max }}{n-1} / \mathrm{RH},
$$

where $n$ is the number of single-level participation evaluation indicators.

\section{B.2.2. Weight by the CRITIC Method}

(1) Determine the standard deviation $\sigma$ of different index

$$
\sigma=\sqrt{\frac{1}{m} \sum_{i=1}^{m}\left(a_{i}-\bar{a}\right)^{2}}
$$

where $m$ is the number of samples of the same index. $a_{i}$ is the index value of the $i$ th sample. $\bar{a}$ is the average value of $m$ samples.

(2) Determine the conflict representative value $\rho_{\mathrm{ab}}$ between indices $a$ and $b$

$$
\begin{gathered}
\rho_{a b}=\frac{\sum_{i=1}^{m}\left(a_{i}-\bar{a}\right)\left(b_{i}-\bar{b}\right)}{\sqrt{\sum_{i=1}^{m}\left(a_{i}-\bar{a}\right)^{2}} \sqrt{\sum_{i=1}^{m}\left(b_{i}-\bar{b}\right)^{2}}}, \\
\eta_{a b}=1-\rho_{a b}
\end{gathered}
$$

where $\rho_{a b}$ is the correlation coefficient of $a$ and $b . b_{i}$ is the index value of the $i$ th sample. $\bar{b}$ is the average value of $m$ samples. $\eta_{a b}$ is the conflict value between $a$ and $b$.

(3) Calculate information value

$$
G_{i}=\sigma \sum_{i=1}^{m}\left(1-\rho_{i j}\right)
$$

where $\rho_{i j}$ is the correlation coefficient of index $i$ and index $j$.

(4) Calculate the weight value of index $i$
TABLE 30: Consistency index RI.

\begin{tabular}{lcccccccccc}
\hline Matrix order & 1 & 2 & 3 & 4 & 5 & 6 & 7 & 8 & 9 & 10 \\
\hline RI & 0 & 0 & 0.58 & 0.90 & 1.12 & 1.24 & 1.32 & 1.41 & 1.45 & 1.49 \\
\hline & & & \\
& & & & \\
& $W_{i}=\frac{G_{i}}{\sum_{i=1}^{n} G_{i}}$. & & & & & (B.11)
\end{tabular}

\section{B.2.3. Fusion Weight by Game Theory}

(1) The vector composed of the weights of $L$ indexes is

$$
u(k)=\left\{u_{k 1}, u_{k 2}, \cdots, u_{k n}\right\}\{k=1,2, . ., L\} .
$$

(2) The linear combination of $L$ weight vectors is

$$
u=\sum_{k=1}^{L} \alpha_{k} u_{k}^{T}
$$

where $\alpha=\left\{\alpha_{1}, \alpha_{2}, \cdots, \alpha_{L}\right\}$ is the linear combination coefficient. $\left\{u \mid u=\sum_{k=1}^{L} \alpha_{k} u_{k}, \alpha_{k}>0\right\}$ is the set of possible weights.

(3) In order to select the most satisfactory weight in $u$, the linear combination coefficient $\alpha_{k}$ of should be optimized to minimize the difference value between $u$ and $u_{k}$. The objective function is

$$
\min \left\|\sum_{k=1}^{n} \alpha_{k} u_{k}^{T}-u_{k}^{T}\right\|, k=1,2, \cdots, L .
$$

(4) The optimal first derivative condition is

$$
\sum_{j=1}^{L} \alpha_{j} u_{i} u_{j}^{T}=u_{i} u_{i}^{T}(i=1,2, \cdots, L)
$$

(5) The optimized combination coefficient $\left(\alpha_{1}, \alpha_{2}, \cdots, \alpha_{L}\right)$ is normalized to obtain $\alpha^{*}=\alpha_{k} / \sum_{k=1}^{L} \alpha_{k}$. Finally, the fusion weight $u^{*}$ is obtained, namely,

$$
u^{*}=\sum_{k=1}^{L} \alpha_{k}^{*} u_{k}^{T}, k=1,2, \cdots L
$$

B.3. Comprehensive Utility Ranking Based on the CWVIKOR Method 
(1) Determine the positive ideal solution $P^{*}$ and negative ideal solution $P^{-}$of each index.

$$
\begin{aligned}
& P^{*}=\left\{y^{*}\right\}=\max _{i=1}^{n}\left(y_{i j}\right), \\
& P^{-}=\left\{y^{-}\right\}=\min _{i=1}^{n}\left(y_{i j}\right)
\end{aligned}
$$

where $y_{i j}$ is the normalized value of the index.

(2) The group benefit value $S_{i}$ and the maximum individual regret value $R_{i}$ are calculated.

$$
\begin{aligned}
& S_{i}=\sum_{j=1}^{m} \omega_{i} \frac{\left(y_{j}^{*}-y_{i j}\right)}{\left(y_{j}^{*}-y_{j}^{-}\right)}, \\
& R_{i}=\max _{j} \omega_{i} \frac{\left(y_{j}^{*}-y_{i j}\right)}{\left(y_{j}^{*}-y_{j}^{-}\right)}
\end{aligned}
$$

where $\omega_{i}$ is the fusion weight determined by the game theory. The smaller $S_{i}$ is, the higher the group benefit of regional water resource life cycle utility is. The smaller $R_{i}$ is, the smaller individual regret of regional water resource life cycle utility is.

(3) The comprehensive utility value of water resource life cycle sustainability is calculated

$$
\begin{gathered}
Q_{i}=v \frac{S_{i}-S^{-}}{S^{*}-S^{-}}+(1-v) \frac{R_{i}-R^{-}}{R^{*}-R^{-}}, \\
S^{*}=\max _{i}\left\{S_{i}\right\}, S^{-}=\min _{i}\left\{S_{i}\right\} ; R^{*}=\max _{i}\left\{R_{i}\right\}, R^{-}=\min _{i}\left\{R_{i}\right\} .
\end{gathered}
$$

$v$ is the utility decision coefficient, which is used to measure the subjective preference of decision makers. If $v>0.5$, the decision of the overall optimal utility is preferred. If $v<0.5$ , the decision that pays more attention to minimum individual regret value is preferred. In this paper, $v=0.5$ is selected to evaluate the utility of water resources life cycle in a halfmeasure way. The smaller the $Q_{i}$ value is, the higher the comprehensive utility value of water resource life cycle sustainability is.

(4) Sort according to the values of $Q_{i}, S_{i}$, and $R_{i}$. The smallest value is the best value of utility.

\section{Data Availability}

All data are presented in the article and appendices.

\section{Conflicts of Interest}

The authors declare no conflict of interest.

\section{Acknowledgments}

This work was supported by the National Key Research and Development Program (No. 2018YFC0406406); the Natural Science Foundation of China (No. 41807195), and China Postdoctoral Science Foundation (Nos. 2019M661053 and 2020T130390).

\section{References}

[1] L. Chai, X. Liao, L. Yang, and X. Yan, "Assessing life cycle water use and pollution of coal-fired power generation in China using input-output analysis," Applied Energy, vol. 231, pp. 951-958, 2018.

[2] Z. Zhou, H. Jiang, and L. Qin, "Life cycle sustainability assessment of fuels," Fuel, vol. 86, no. 1-2, pp. 256-263, 2007.

[3] W. Kloepffer, "Life cycle sustainability assessment of products," Ecomed, vol. 13, no. 2, 2008.

[4] D. Hunkeler, "Societal LCA methodology and case study (12 pp)," The International Journal of Life Cycle Assessment, vol. 11, no. 6, pp. 371-382, 2006.

[5] Z. Chen, H. H. Ngo, and W. Guo, "A critical review on sustainability assessment of recycled water schemes," Sci. Total Environ, vol. 426, pp. 13-31, 2012.

[6] X. J. Deng, Y. P. Xu, L. F. Han, Z. H. Yu, M. N. Yang, and G. B. Pan, "Assessment of river health based on an improved entropy-based fuzzy matter- element model in the Taihu Plain, China," Ecological Indicators, vol. 57, pp. 85-95, 2015.

[7] D. Hering, L. Carvalho, and C. Argillier, "Managing aquatic ecosystems and water resources under multiple stress-an introduction to the MARS project," Science of the Total Environment, vol. 503, pp. 10-21, 2015.

[8] M. M. Mekonnen and A. Y. Hoekstra, "The green, blue and grey water footprint of crops and derived crop products," Hydrology and Earth System Sciences, vol. 15, no. 5, pp. 1577-1600, 2011.

[9] A. Y. Hoekstra, "A critique on the water-scarcity weighted water footprint in LCA," Ecological Indicators, vol. 66, pp. 564-573, 2016.

[10] P. W. Gerbens-Leenes, L. Xu, G. J. de Vries, and A. Y. Hoekstra, "The blue water footprint and land use of biofuels from algae," Water Resources Research, vol. 50, no. 11, pp. 8549-8563, 2014.

[11] M. M. Mekonnen, P. Gerbens-Leenes, and A. Y. Hoekstra, "The consumptive water footprint of electricity and heat: a global assessment," Environmental Science: Water Research \& Technology, vol. 1, pp. 285-297, 2015.

[12] E. Nogueira Junior, M. Kumar, S. Pankratz, A. O. Oyedun, and A. Kumar, "Development of life cycle water footprints for the production of fuels and chemicals from algae biomass," Water Research, vol. 140, pp. 311-322, 2018.

[13] Q. Yang, J. Liang, J. Li, H. Yang, and H. Chen, "Life cycle water use of a biomass-based pyrolysis polygeneration system in China," Applied Energy, vol. 224, pp. 469-480, 2018.

[14] X. Jia, P. S. Varbanov, J. J. Klemeš, and S. R. Wan Alwi, "Water availability footprint addressing water quality," Journal of Sustainable Development of Energy, Water and Environment Systems, vol. 7, no. 1, pp. 72-86, 2019.

[15] M. B. Johnson and M. Mehrvar, "An assessment of the grey water footprint of winery wastewater in the Niagara Region 
of Ontario, Canada," Journal of Cleaner Production, vol. 214, pp. 623-632, 2019.

[16] R. L. Zhou, L. Gao, Z. Q. Guo, D. F. Cui, and J. C. Yang, "Underground direct treatment and recycle of coal mine water," China Water \& Wasterwater, vol. 29, no. 4, pp. 7174, 2013.

[17] D. Z. Gu, Y. Zhang, and Z. G. Cao, "Technical progress of water resource protection and utilization by coal mining in China," Coal Science and Technology, vol. 44, no. 1, pp. 1-7, 2016.

[18] W. D. Mao, R. L. Zhou, and Z. Q. Guo, "Zero liquid discharge treatment technology and application for coal mine drainage water," Coal Science and Technology, vol. 45, no. 11, pp. 205210, 2017.

[19] X. W. He, X. H. Zhang, and F. Q. Li, "Comprehensive utilization system and technical innovation of coal mine water resources," Coal Science and Technology, vol. 46, no. 9, pp. 4-11, 2018.

[20] N. Ding, X. H. Lu, J. X. Yang, and B. Lu, "Water footprint of coal production," Acta Science Circumstantiae, vol. 36, no. 11, pp. 4228-4233, 2016.

[21] M. Lundin, M. Bengtsson, and S. Molander, "Life cycle assessment of wastewater systems: Influence of system boundaries and scale on calculated environmental loads," Environmental Science \& Technology, vol. 34, no. 1, pp. 180-186, 2000.

[22] R. B. Wang, Study on the added-value of water resources under the life-cycle condition, [Ph.D. thesis], Chinese Academy of Agricultural Sciences, Beijing, 2011.

[23] C. X. Zhao, Study on the game theory of human-water harmony and its applications, [Ph.D. thesis], PhD dissertation, Zhengzhou, 2010.

[24] C. Zhang and L. D. Anadon, "Life cycle water use of energy production and its environmental impacts in China," Environmental Science \& Technology, vol. 47, no. 24, pp. 14459-14467, 2013.

[25] L. Tong, X. Liu, X. Liu, Z. Yuan, and Q. Zhang, "Life cycle assessment of water reuse systems in an industrial park," Journal of Environmental Management, vol. 129, pp. 471-478, 2013.

[26] B. Godskesen, Sustainability evaluation of water supply technologies: By using life-cycle and freshwater withdrawal impact assessment \& multi-criteria decision analysis, DTU Environment, 2012.

[27] P. Bhakar and A. P. Singh, "Life cycle assessment of groundwater supply system in a hyper-arid region of India," Procedia CIRP, vol. 69, pp. 603-608, 2018.

[28] X. Xue, S. Cashman, A. Gaglione et al., "Holistic analysis of urban water systems in the Greater Cincinnati region: (1) life cycle assessment and cost implications," Water Research $X$, vol. 2, p. 100015, 2019.

[29] M. Hadjikakou, B. D. Stanford, T. Wiedmann et al., “A flexible framework for assessing the sustainability of alternative water supply options," Science of the total environment, vol. 671, pp. 1257-1268, 2019.

[30] M. García-Sánchez and L. P. Güereca, "Environmental and social life cycle assessment of urban water systems: The case of Mexico City," Science of The Total Environment, vol. 693, p. 133464, 2019.

[31] Y. Xue, J. Liu, P. G. Ranjith, X. Liang, and S. Wang, "Investigation of the influence of gas fracturing on fracturing characteristics of coal mass and gas extraction efficiency based on a multi-physical field model," Journal of Petroleum Science and Engineering, vol. 206, article 109018, 2021.

[32] L. Zhu, F. Dang, Y. Xue, K. Jiao, and W. Ding, "Multivariate analysis of effects of microencapsulated phase change materials on mechanical behaviors in light-weight aggregate concrete," Journal of Building Engineering, vol. 42, article 102783, 2021.

[33] A. Hospido, M. T. Moreira, M. Fernández-Couto, and G. Feijoo, "Environmental performance of a municipal wastewater treatment plant," International Journal of Life cycle assessment, vol. 9, no. 4, pp. 261-271, 2004.

[34] B. Q. Zhang, Research on dynamic evaluation system of highefficient utilization of water resources in large openunderground combined mining coal mine based on LCSA theory, [M.S. thesis], Taiyuan University of Technology, Shanxi, China, 2020.

[35] S. Opricovic, Multicriteria Optimization of Civil Engineering Systems, Faculty of Civil Engineering, Belgrade, 1998. 